\title{
Estimation of gas hydrate concentration from multi-component seismic data at sites on the continental margins of NW Svalbard and the Storegga region of Norway
}

\author{
G.K. Westbrook ${ }^{\mathrm{a},{ }^{*}}$, S. Chand ${ }^{\mathrm{f}}$, G. Rossi ${ }^{\mathrm{d}}$, C. Long $^{\mathrm{a}}$, S. Bünz ${ }^{\mathrm{e}}$, A. Camerlenghi ${ }^{\mathrm{d}}$, J.M. \\ Carcione $^{d}$, S. Dean ${ }^{f}$, J.-P. Foucher ${ }^{c}, E^{2}$ Flueh $^{b}$, D. Gei ${ }^{d}$, R.R. Haacke ${ }^{a}$, G. Madrussani $^{d}$, J. \\ Mienert $^{\mathrm{e}}$, T.A. Minshull, ${ }^{f}$ H. Nouzéc ${ }^{\mathrm{c}}$, S. Peacock ${ }^{\mathrm{a}}$, T.J. Reston $^{\mathrm{a}, \mathrm{b}}, \mathrm{M}$. Vanneste ${ }^{\mathrm{e}}$ and M. \\ Zillmer $^{\mathrm{b}}$
}

\author{
a School of Geography, Earth and Environmental Sciences, University of Birmingham, UK \\ ${ }^{b}$ IFM-GEOMAR, Germany \\ ${ }^{c}$ IFREMER, Brest, France \\ d Istituto Nazionale di Oceanografia e di Geofisica Sperimentale, Trieste, Italy \\ e Institute of Geology, University of Tromsø, Norway \\ ${ }^{f}$ National Oceanography Centre, University of Southampton, UK \\ *: Corresponding author : G.K. Westbrook, email address : G.K.WESTBROOK@bham.ac.uk
}

\begin{abstract}
High-resolution seismic experiments, employing arrays of closely spaced, four-component ocean-bottom seismic recorders, were conducted at a site off western Svalbard and a site on the northern margin of the Storegga slide, off Norway to investigate how well seismic data can be used to determine the concentration of methane hydrate beneath the seabed. Data from $P$-waves and from $S$ waves generated by $P-S$ conversion on reflection were inverted for $P$ - and $S$-wave velocity $\left(V_{p}\right.$ and $V_{s}$ ), using $3 \mathrm{D}$ travel-time tomography, $2 \mathrm{D}$ ray-tracing inversion and $1 \mathrm{D}$ waveform inversion. At the NW Svalbard site, positive $V_{p}$ anomalies above a sea-bottom-simulating reflector (BSR) indicate the presence of gas hydrate. A zone containing free gas up to 150-m thick, lying immediately beneath the $\mathrm{BSR}$, is indicated by a large reduction in $V_{\mathrm{p}}$ without significant reduction in $V_{\mathrm{s}}$. At the Storegga site, the lateral and vertical variation in $V_{p}$ and $V_{s}$ and the variation in amplitude and polarity of reflectors indicate a heterogeneous distribution of hydrate that is related to a stratigraphically mediated distribution of free gas beneath the BSR. Derivation of hydrate content from $V_{p}$ and $V_{s}$ was evaluated, using different models for how hydrate affects the seismic properties of the sediment host and different approaches for estimating the background-velocity of the sediment host. The error in the average $V_{p}$ of an interval of $20-\mathrm{m}$ thickness is about $2.5 \%$, at $95 \%$ confidence, and yields a resolution of hydrate concentration of about $3 \%$, if hydrate forms a connected framework, or about $7 \%$, if it is both porefilling and framework-forming. At NW Svalbard, in a zone about 90-m thick above the BSR, a Biottheory-based method predicts hydrate concentrations of up to $11 \%$ of pore space, and an effectivemedium-based method predicts concentrations of up to $6 \%$, if hydrate forms a connected framework, or $12 \%$, if hydrate is both pore-filling and framework-forming. At Storegga, hydrate concentrations of up to $10 \%$ or $20 \%$ were predicted, depending on the hydrate model, in a zone about $120-\mathrm{m}$ thick above a BSR. With seismic techniques alone, we can only estimate with any confidence the average hydrate content of broad intervals containing more than one layer, not only because of the uncertainty in the layer-by-layer variation in lithology, but also because of the negative correlation in the errors of estimation of velocity between adjacent layers. In this investigation, an interval of about 20-m thickness (equivalent to between 2 and 5 layers in the model used for waveform inversion) was the smallest within which one could sensibly estimate the hydrate content. If lithological layering much thinner than 20-m thickness controls hydrate content, then hydrate concentrations within layers could significantly exceed or fall below the average values derived from seismic data.
\end{abstract}

Keywords: $P$-wave; S-wave; Seismic velocity; Hydrate concentration; Continental margin

\section{Introduction}

The seismic reflection technique is the most widely used method for remotely detecting and quantifying gas hydrate beneath continental margins. This has been done primarily through the 
imaging of the bottom-simulating reflector (BSR) that is caused by the presence of free gas at the base of the hydrate stability field (e.g. Shipley et al. (1979) and many subsequent papers). While the BSR provides an easily recognisable indicator of the presence of hydrate, it does not provide information directly on the concentration of hydrate or its distribution in the region between the BSR and the seabed. Estimates of hydrate concentration have commonly been derived from seismic velocity (primarily $P$-wave velocity, $\mathrm{Vp}$ ), obtained through the analysis and/or modelling of data from a multi-channel seismic streamer, using techniques such as onedimensional waveform inversion (Singh et al., 1993). The general approach is to define velocity as a function of depth and horizontal position, and to subtract from this a background velocity function, which is that expected in the absence of hydrate. Where the measured velocity is higher than the background velocity, the difference in velocity is used to estimate the concentration of hydrate, according to some model of how the presence of hydrate in sediment affects its seismic velocity. There are several limitations to this approach:

1. The accuracy of definition of seismic velocity can be limited by

a) insufficient offset between the source and farthest receiver for the depths of reflectors of interest (Commonly, industry surveys have large offset but low frequency, while highresolution surveys have a ranges of offset that are too short for the water depth.),

b) low dominant frequency of the source wavelet (Most industry surveys designed for petroleum exploration have targets far deeper than the region between the BSR and the seabed, and use lower frequency sources than would be ideal for the first few hundred metres below the seabed.),

c) deviation of the shapes of the reflectors from simple, parallel planes (This can be overcome by ray tracing and pre-stack depth migration, but these techniques have not been employed commonly.),

d) assumptions inherent in the velocity model, such as the assumption that layers are of constant velocity where velocity actually varies with depth or laterally within each layer. 
2. Insufficient knowledge of the background velocity function is a major problem. General, empirically derived velocity/depth functions, such as those of Hamilton (1980), cannot be used with any degree of confidence, because local variations in lithology and compaction history produce variations in velocity that are of equal magnitude to, or greater than, those that may be caused by the presence of hydrate. Ideally, a background velocity function would be derived from the same sediment sequence at an adjacent site where hydrate was not present. However, to establish the absence of hydrate at such a reference site, without independent validation from a well or similar control, is as uncertain as establishing its presence at low concentration.

3. Quantifying the amount of hydrate present in sediment from the deviation of seismic velocity from its expected background value is crucially dependent upon the model used to predict how hydrate affects seismic velocity. Hydrate may replace pore water without affecting the framework of grains or it may cement the grains and/or support the grain framework in various ways. The way in which hydrate affects velocity, and the extent to which it does so, may depend on lithology and the degree of saturation of hydrate.

The purpose of the investigations off Svalbard and Norway was to examine the viability of seismic techniques in the detection and quantification of methane hydrate in continental margins (Westbrook et al., 2004; Westbrook et al., 2005). Data were collected to evaluate $S$-wave velocity (Vs), $P$ - and $S$-wave quality factors (Qp and Qs), and seismic anisotropy, in addition to $P$-wave velocity $(\mathrm{Vp})$ and $P$-wave imaging. The techniques employed to derive the sub-surface distribution of seismic properties, included 1D waveform inversion, 2D travel-time inversion, 3D tomography and pre-stack depth migration. The basic design of the seismic surveys was one of an array of about twenty 4-component (three orthogonal geophones and a hydrophone) ocean-bottom seismic recorders (OBS), spaced at 400-m intervals. The array was crossed by a dense pattern of shot lines with 200-m spacing, using a high resolution seismic source $(2 \times 0.65$ litre sleeve guns), shot at intervals of $\leq 25 \mathrm{~m}$, along which seismic reflection profiles were acquired with a short seismic streamer. The use of three orthogonal geophones enabled the 
recording of $S$ waves as well as $P$ waves. From the distribution of seismic properties beneath the seabed, obtained with one or more of the inversion/modelling techniques, the concentrations of methane hydrate in the sediment were derived using effective-medium-based and Biot-theorybased methods (Helgerud et al., 1999; Chand et al., 2004; Carcione et al., 2005). Predictions from these methods were calibrated against published experimental and closely-controlled field data and the results of laboratory experiments by partners in the consortium (Priest et al., 2005a; Priest et al., 2005b; Chand et al., 2006). The project investigated three separate sites where at one, NW Svalbard, a clear and near-continuous BSR was present (Posewang and Mienert, 1999), at another, SW Svalbard, the presence of hydrate was suspected from velocity anomalies near to the predicted base of the hydrate stability zone, although a prominent BSR was not present (Vanneste et al., 2005), and at the third, Storegga, a BSR was discontinuously present (Bünz et al., 2003).

\section{NW Svalbard}

\subsection{Acquisition of seismic data}

The NW Svalbard site lies in a water depth of about $1500 \mathrm{~m}$ on the western continental margin of Svalbard, where it abuts the northern end of the Knipovitch Ridge near its intersection with the Molloy transform (Figure 1). Correlation with the local seismic stratigraphy (Vanneste et al., 2005) indicates that the well-stratified strata visible in the HYDRATECH seismic sections from (Figure 2) belong to the YP-3 sequence and upper part of the YP-2 sequences of Eiken and Hinz (1993), which are interpreted as glacio-marine and hemipelagic beds reworked by contour currents. The regional R3 unconformity, dated at $\sim 0.78 \mathrm{Ma}$, and shown in the nearby seismic line BGR31-74 (Eiken and Hinz, 1993), lies below the reflectors imaged by HYDRATECH, indicating a sedimentation rate greater than $500 \mathrm{~m} / \mathrm{Ma}$. The BSR cuts obliquely across the strata at a depth of about $200 \mathrm{~m}$ below the seabed. These strata show changes in amplitude and, in some cases, polarity, where they are crossed by the BSR, presumably as a consequence of a 
change from partial filling of pore space by free gas beneath the BSR to hydrate above it (Figure 2). The array of OBS was situated over a section of sedimentary horizons gently dipping SW at $2^{\circ}$, bounded by antithetic normal faults. $P$-wave reflections from the stratal reflectors and the BSR were recorded clearly by the OBS (Figure 3), as were $S$ waves created by mode-conversion from $P$ waves on reflection (Figure 4). Synthetic modelling demonstrated that $S$ waves created by conversion on transmission at or near the seabed have very low amplitude in comparison to those created by conversion on reflection (Figure 5).

[Figure 1]

[Figure 2]

[Figure 3]

[Figure 4]

[Figure 5]

\subsection{Inversion for $V p$ and $V s$}

The arrival times of pre-critical $P$ reflections and $P$-S converted waves from up to 15 reflectors (including the BSR for $P$, but not for $P S$, which did not provide a coherent seismic event), were picked and inverted using 2D ray tracing (Zelt and Smith, 1992) and 3D tomography (Rossi and Vesnaver, 2001; Rossi et al., 2005). Refracted arrivals and post-critical reflections were not used, because of the uncertainty of correlation with the pre-critical reflections and because the crossing and consequent interference between these phases hinders clear picking of arrival times. One-dimensional waveform inversion was performed on the records from shot lines parallel to strike at three OBS, using the results of travel-time inversion to provide starting models. 
All the different analyses of Vp gave similar functions of velocity with depth (Figure 6): a general increase of $\mathrm{Vp}$ with depth down to the BSR, beneath which there is a sharp reduction in velocity, from values in the region of $1800 \mathrm{~m} / \mathrm{s}$ to between 1500 and $1600 \mathrm{~m} / \mathrm{s}$ in a zone about 10-30 m thick, underlain by a gradual return to higher values with increasing depth. The velocity change across each layer boundary is in agreement with the polarity of the reflection from the boundary. A summary of the analysis of the errors in velocity derived in the traveltime inversion is given in Appendix 1. Relative to the velocity/depth curve of Hamilton (1980) for terrigenous sediment, a zone about 100-m thick above the BSR has greater than expected Vp and a zone of about 150-m thick below the BSR has lower than expected Vp. The thickness of the low-velocity zone immediately beneath the BSR varies in the dip-parallel profile from 165 m beneath OBS 635 to $120 \mathrm{~m}$ beneath OBS 652 (see Figure 2), as the BSR obliquely intersects the stratal reflectors. Individual layers show large changes in velocity where they are intersected by the BSR. For example, Vp for a layer changes from being $1520 \mathrm{~m} / \mathrm{s}$ below the BSR to 1820 $\mathrm{m} / \mathrm{s}$ above it, and the layer-bounding reflectors change their polarity.

[Figure 6]

3D tomographic inversion, using the staggered grid method, was undertaken with a model comprising ten layers beneath the seabed. With this method, a coarse grid is chosen, such that the ray coverage in each cell is similar and high. A series of inversion is made, with small shifts applied in $\mathrm{x}$ and $\mathrm{y}$ directions between each inversion. The resulting velocity fields are averaged over a grid with a spacing equal to the $\mathrm{x}$ and $\mathrm{y}$ shifts to obtain an image that has a higher resolution than the base grid, without the unwanted effect of poor coverage (Vesnaver and Böhm, 2000). We used base grids of $1.2 \mathrm{~km}$ cell size, shifted along $\mathrm{x}$ and $\mathrm{y}$ axis, to obtain a total of 15 different models, from which the resulting velocity fields were averaged to produce a final model with an effective cell width of $120 \mathrm{~m}$ in its central region. The number of rays per cell in 
the base grid varies between about 1600 to more than 18000 . The layers, defined by the reflectors, vary in thickness between 20 and $70 \mathrm{~m}$. In addition to the travel times recorded by the OBS, the model was constrained by the travel times to the reflectors recorded with the ship's hydrophone streamer.

The results of the tomographic inversion show the pattern of interference between the velocity distribution related to the porosity and lithology of the sedimentary layers, with a general downward increase in velocity, and that related to the BSR, with a small increase in velocity above it produced by the hydrate, and a large decrease below it produced by free gas (Figure 7). The lateral variation in velocity in the hydrate- and gas-affected zones may be related to the migration pathways of gas-rich fluid and be a characteristic of hydrate systems.

[Figure 7]

[Figure 8]

The variation of Vs was found from 2D ray-traced or tomographic inversion of the travel times of the $P S$ converted waves (Figure 4). This required the correlation of the $P S$ arrivals with their corresponding $P$ arrivals, which is potentially the major source of uncertainty in the inversion. Initially, the correlation was based on the relative travel times and the amplitudes of $P S$ reflections in comparison with those of the $P$ reflections. In the 2D ray-tracing inversion, the $S$ wave velocities were derived using the optimal Vp model and varying Poisson's ratio for each layer to obtain the best fit between the observed and model $P S$ travel times. The validity of correlations between $P$ and $P S$ reflections was assessed by examining the $P S$ residuals for systematic variation, by checking for improbable values of Poisson's ratio and by testing other plausible correlations of $P$ and $P S$. In the tomographic model, the $P S$ travel times were inverted, with the reflector geometry and $\mathrm{Vp}$ fixed at the values found for the inversion of the $P$ travel 
times, to obtain Vs in each of its cells from the up-going ray-segments. The boundary between the uppermost two sediment layers in the Vp model did not give clear PS arrivals, so these two layers could not be modelled separately for Vs, and were given the same value of Poisson's ratio in the model. Consequently, the value of Vs for the top layer is almost certainly overestimated and the value of Vs for the second layer underestimated. Studies of Vs in marine sediments have shown that it increases with depth rapidly from very low values in unconsolidated sediment at the seabed (e.g. Nolet and Dorman, 1996). A likely variation in Vs with depth in the top two layers that has the same travel-time delay as the model, and is similar to that found in comparable marine sediments elsewhere, is shown by the dark blue curve in Figure 8. A very low value of Vs at the seabed is corroborated by the absence in the data of any distinguishable $S$ waves caused by $P-S$ conversion on transmission at the seabed (Figure 5).

$S$-wave velocity generally increases with depth through the region of the BSR, without any large decrease (Figure 8). The presence of the BSR, if it is indicated in any way by Vs, is shown by a more rapid increase in velocity in the $50 \mathrm{~m}$ above it and a zone of no increase or slight decrease, as shown by waveform inversion, in the $50 \mathrm{~m}$ beneath it. This is consistent with the cause of the pronounced decrease in $\mathrm{Vp}$ beneath the BSR being the presence of free gas at a concentration too low to have a detectable effect on the density, and indicates that if hydrate acts to cement grains and increase the shear modulus of the sediment then the amount of hydrate present is low. Another aspect of the $S$-wave data is that they show azimuthally dependent $S$-wave splitting (Haacke et al., 2005; Haacke and Westbrook, 2006), which, at the NW Svalbard site, is most strongly developed in a zone between seabed and a depth of $100 \mathrm{~m}$, where the average $S$ wave anisotropy is approximately $1.0 \%$. The $S$-wave splitting is probably caused by a set of near-vertical cracks aligned parallel to the fast Vs direction. The orientations of the fast Vs direction, shown by data from six OBS, range between $080^{\circ}$ and $140^{\circ}$ (clockwise from North). These near-vertical cracks potentially provide migration pathways for both liquid and gas through the low-permeability hemipelagic layers in the sediment sequence. 


\subsection{Derivation of hydrate content from $V p$ and $V s$}

The concentration of methane hydrate present was calculated from the velocity models using two approaches, differential effective medium theory (Chand et al., 2004; Chand et al., 2006) and a Biot-type three-phase theory (Carcione et al., 2005). With both techniques, the variation in $\mathrm{Vp}$ and Vs with depth in the absence of hydrate is calculated from the variation in porosity with depth and the densities and elastic moduli of the constituent minerals. These were obtained from the mineral content of the same sediment sequence where it has been drilled at ODP site 986 (Jansen et al., 1996), farther south along the western Svalbard margin (Figure 1a) and also from the mineral content of sediment sampled with gravity cores at the site of the seismic survey. The changes in $\mathrm{Vp}$ and Vs caused by the presence of hydrate were calculated according to different models of how hydrate affects the elastic properties of the rock framework and pore fill.

For the differential effective medium (DEM) approach, the seismic properties of clay-rich hydrate-bearing sediment are related to its porosity, mineralogy, microstructure, clay-particle anisotropy and hydrate saturation. It uses self-consistent approximation theory (SCA) to create a bi-connected composite and a DEM theory to adjust the composition to that of the sediment. For predicting the effect of hydrate content, the DEM model has a variety of forms depending on whether hydrate is considered to form a connected framework or reside, unconnected in pore space. The connected-hydrate case is implemented using clay and hydrate as the bi-connected composite, created using SCA, instead of clay and water. Two models were implemented with the DEM approach. In one, the frame-only model, all the hydrate forms a connected, loadbearing frame. In the other, the frame-plus-pore model, part of the hydrate forms a frame and the remainder forms pore-filling inclusions (Chand et al., 2006). In the latter model, the proportion of frame-forming hydrate was increased linearly with hydrate saturation, from $1 \%$ of the total hydrate at $1 \%$ hydrate saturation to $100 \%$ at $100 \%$ hydrate saturation; so, in this model, hydrate is predominantly pore filling at low saturation. Hydrate concentration was obtained by 
changing its value at each depth until the predicted values of $\mathrm{Vp}$ and $\mathrm{Vs}$ for that depth gave the best least-squares match to the values derived from analysis of the seismic data.

For the Biot-type three-phase theory, there are two solid frames (one for grains and one for gas hydrate) and a fluid. The resulting $P$-wave dispersion relation constitutes a generalization of the Gassmann equation for two frames and one fluid at the low-frequency limit of the theory, thus neglecting dissipation, where grains, hydrate and water move in phase. The model is based on the assumption that hydrate occupies the pore space and is interconnected. It was calibrated for the bulk and rigidity moduli of the host sediment at full water saturation. The values of Vs and Vp obtained from the seismic data were used to derive the variation in Poisson's ratio for the wet sediment, which is an intrinsic constituent of the model (Carcione et al., 2005). Hydrate content was derived from the anomalies in $\mathrm{Vp}$, obtained from the difference between the tomographically derived $\mathrm{Vp}$ and the predicted background value of $\mathrm{Vp}$ (Carcione et al., 2005).

[Figure 9]

\section{Background-velocity function}

In addition to the choice of model for hydrate prediction, the estimation of hydrate concentration is dependent upon the function representing the background variation of $\mathrm{Vp}$ and Vs with depth, in the absence of hydrate. The Vs function may be explicit, as in the DEM model, or implicit, as in the variation of Poisson's ratio with depth in the Biot-type model. Five different background-velocity functions were used to explore the sensitivity of the choice of background-velocity function upon the derivation of hydrate concentration using the DEM approach (Figure 9). Three of the background-velocity functions were derived by using the DEM model to predict velocity in the absence of hydrate with the porosity/depth data from ODP site 986 . The adequate prediction of the variation with depth of $\mathrm{Vp}$ measured at site 986 was the test of the model. Unfortunately, Vs was not measured at ODP site 986. The DEM-1 background-velocity functions for $\mathrm{Vp}$ and $\mathrm{Vs}$ are based on the mineral content of cores from 
ODP site 986. DEM-2 uses the mineral content of gravity cores taken close to the OBS array. DEM-3 is similar to DEM-2, but is constrained to give a Vs background values that are lower than the observed values of Vs at the Svalbard site in the uppermost $60 \mathrm{~m}$ to avoid the prediction of reduced or even negative values of hydrate concentration where observed values of Vs are less than the background values. The $P$-velocity/depth curve of Hamilton (1980) was used as a background-velocity function for the purpose of comparison. There is no a priori reason to expect that it is appropriate, beyond it being broadly representative of the behaviour of the fine-grained terrigenous sediment that occurs at the site. The background-velocity function used for the Biot-type model of Carcione et al. (2005) is included to compare the results from the two DEM hydrate models with those of the Biot-type model. The degree to which the predicted hydrate concentration is affected by the background velocity function is greatest in the uppermost $85 \mathrm{~m}$ of the section at Svalbard, where hydrate may or may not be predicted to be present, according to which function is used. In the top layer, all background velocity functions, except DEM-3, predict a higher than observed velocity and hence a negative concentration of hydrate. This is primarily because the exponential curves fitted to the porosity data from ODP site 986 used in the models underestimate porosity near the seabed. For the second layer, the Hamilton and the Carcione et al. velocity functions yield negative hydrate concentrations and DEM-1 and DEM-2 produce near-zero concentrations. In both the top layers, DEM-3 gives positive values of hydrate concentration. This is because, in trying to make all Vs background values less than the observed values of Vs between the seabed and the BSR, the values of velocity from the background functions for both $\mathrm{Vs}$ and $\mathrm{Vp}$, which are tied through the DEM model, are too low. The background Vs should match the observed Vs below the BSR, but DEM-3 predicts lower values than the observed values in the first four layers beneath the BSR. A background function intermediate between DEM-2 and DEM-3 would best satisfy the constraints provided by the available information on the seismic properties of the sediment sequence at Svalbard. 
The variation in hydrate concentration with depth at the position of OBS 639, as predicted by the DEM approach applied to the velocity variation with depth obtained from 2D ray-tracing inversion, shows up to $6 \%$ of pore space for the frame-only model and up to $13 \%$ for the frameplus-pore model, occurring primarily in a zone about 90-m thick just above the BSR (Figure 9). These values depend on the choice of background-velocity function, as discussed above. Using background-velocity function DEM-1, application of the frame-only model to the velocity section obtained for the central part of Line 4 beneath OBS 644, 648 and 652 yields a crosssectional distribution of hydrate concentration (Figure 10) that is consistent with the distribution of hydrate with depth derived at OBS 639 and shows lateral variation of a few percent, the higher concentration being upslope.

[Figure 10]

In that part of the tomographic model that lies within the area of the OBS array, a hydrate concentration of up to $17 \%$ of pore space was predicted with the Biot-type model (Figure 11), but the high concentrations shown at the tops of the layers and low concentrations at their bases are artefacts of applying a continuous function of predicted $\mathrm{Vp}$ to the relatively thick layers of constant velocity in the velocity model. The values at the middle of each layer are valid, however, giving a maximum concentration of about $11 \%$, for the layer just above the BSR. By comparison, the DEM frame-plus-pore model, used with the Vp background function for the Biot-type model, predicted a concentration of about $9 \%$ for this layer (Figure 9). In Figure 11, the second layer beneath the seabed appears to show the presence of hydrate at its top, but this again is an artefact of the discontinuous velocity model being compared with a continuous background model. The predicted value of hydrate concentration at the layer's centre is zero and in its lower half it is negative, which is not physically allowed. In the 2D ray-trace model, two layers represent this problematic layer and only in the lower of these two layers does the hydrate concentration (at 1\%) just exceed zero, with the background function used for the Biot-type 
model. Beneath the BSR, from the reduction in Vp below background, a maximum free-gas saturation of $0.4 \%$ was predicted for a uniform mixture of free gas and water (Wood's model, described in Mavko et al., 1998), as shown in Figure 11, and 9\% was predicted for a patchydistribution of gas (Hill's model).

[Figure 11]

\section{Effects of errors in measurement of seismic velocity}

The effects of errors in the derivation of seismic velocity compound the variation in the predicted values of hydrate arising from the choice of hydrate model and background-velocity functions. The estimates of the error in $V p$ for the three layers immediately above the BSR in the $2 \mathrm{D}$ ray-tracing model of line 4 , from which the hydrate concentrations of Figure 10 were derived, are $3.2 \%(58 \mathrm{~m} / \mathrm{s}), 1.5 \%(26 \mathrm{~m} / \mathrm{s})$ and $1.2 \%(21 \mathrm{~m} / \mathrm{s})$, respectively, at $95 \%$ confidence (Appendix 1). After subtraction of different background functions for $\mathrm{Vp}$ from the velocities of the seismic model, these errors in Vp yield variation in hydrate concentration for the frame-only model and for the frame-plus-pore model as shown below (Table 1). The variation in these estimates of uncertainty in the concentration of hydrate arises from the choices made concerning the appropriate model for the effect of hydrate on velocity and background velocity, each of which has its own justification. For example, excluding the background-velocity function DEM1, which uses mineral content from ODP site 986 rather than local cores, reduces the maximum value of hydrate predicted in the layer immediately above the BSR to $27.1 \%$ for the frame-pluspore model and $13.4 \%$ for the frame-only model. 


\begin{tabular}{|c|c|c|c|c|c|c|c|}
\hline \multicolumn{8}{|c|}{ Table 1} \\
\hline \multirow{2}{*}{$\begin{array}{l}\text { Layer } \\
\text { above } \\
\text { BSR }\end{array}$} & \multirow{2}{*}{$\begin{array}{l}\text { Hydrate } \\
\text { Model }\end{array}$} & \multirow{2}{*}{$\begin{array}{l}\text { Thickness } \\
\text { (m) } \\
\text { SW NE }\end{array}$} & \multicolumn{5}{|c|}{ Background (Reference) Velocity Functions } \\
\hline & & & DEM-1 & DEM-2 & DEM-3 & Hamilton & $\begin{array}{l}\text { Carcione et } \\
\text { al. }\end{array}$ \\
\hline 3 & $\begin{array}{l}\text { Frame } \\
\text { only } \\
\text { Frame } \\
+ \text { pore }\end{array}$ & $37-38$ & $\begin{array}{l}3.5-5.9 \\
8.2-12.8\end{array}$ & $\begin{array}{l}2.7-4.7 \\
6.5-10.7\end{array}$ & $\begin{array}{l}3.4-5.8 \\
8.1-12.7\end{array}$ & $\begin{array}{l}2.1-4.1 \\
5.2-9.6\end{array}$ & $\begin{array}{l}2.1-4.1 \\
5.2-9.6\end{array}$ \\
\hline 2 & $\begin{array}{l}\text { Frame } \\
\text { only } \\
\text { Frame } \\
+ \text { pore }\end{array}$ & $26-27$ & $\begin{array}{l}3.5-7.0 \\
8.3-14.9\end{array}$ & $\begin{array}{l}2.7-5.3 \\
6.4-11.8\end{array}$ & $\begin{array}{l}2.9-5.7 \\
7.1-12.6\end{array}$ & $\begin{array}{l}2.5-5.1 \\
6.0-11.3\end{array}$ & $\begin{array}{l}2.8-5.5 \\
6.7-12.0\end{array}$ \\
\hline 1 & $\begin{array}{l}\text { Frame } \\
\text { only } \\
\text { Frame } \\
+ \text { pore }\end{array}$ & $28-21$ & $\begin{array}{l}2.9-16.7 \\
7.1-33.6\end{array}$ & $\begin{array}{l}2.0-12.1 \\
4.8-24.7\end{array}$ & $\begin{array}{l}2.0-12.1 \\
4.8-24.7\end{array}$ & $\begin{array}{l}2.0-12.1 \\
4.8-24.7\end{array}$ & $\begin{array}{l}2.3-13.4 \\
5.6-27.1\end{array}$ \\
\hline $\begin{array}{l}\text { Rang } \\
\text { BSR } \\
\text { form }\end{array}$ & $\begin{array}{l}\text { of hyc } \\
t \text { are } \\
n \text { mo }\end{array}$ & $\begin{array}{l}\text { concel } \\
\text { le witl } \\
\text { ad bacl }\end{array}$ & $\begin{array}{l}\text { ion (\% } \\
5 \% \text { er } \\
\text { und ve } \\
\text { ydrate. }\end{array}$ & $\begin{array}{l}\text { space) } \\
\text { inds of } \\
\text { functi }\end{array}$ & $\begin{array}{l}\text { three } \\
\text { r each } \\
\text { predi }\end{array}$ & ccorc & $\begin{array}{l}\text { above the } \\
\text { he hydrate } \\
\text { tion in } V p\end{array}$ \\
\hline
\end{tabular}

[Figure 12]

\section{Waveform inversion}

Velocity/depth curves derived from waveform inversion have the potential to give more detailed information on the distribution of hydrate with depth at the scale of the individual layers that generate the $P$ and $S$ reflections. The waveform inversion technique of Singh et al. (1993) and Minshull et al. (1994), modified to use records from the hydrophone and the vertical and horizontal components of an OBS, was applied to data recorded at OBS 639 from shots along a strike line. The relationship between Vp, Vs and density controls the amplitudes of reflections. In practice, density is poorly determined from this kind of seismic inversion and, so, it was linked to Vp by Hamilton's (1978) relationship for terrigenous sediment. This relationship, however, is invalid in the presence of gas, and so a smoother density function, extrapolating across the gas zone, was also tried. The inversion for Vs was found to be quite insensitive, giving only small local departures from the smooth starting model derived from the ray-tracing 
inversion. With an inversion for Vp, in which Vs was related to Vp through Castagna's (1985) relationship for mud rocks and density was derived from Hamilton's (1978) relationship, a high content of hydrate (up to 8.5\%) is obtained above the BSR, using DEM-1 for background with the DEM frame-only model. This inversion gave a false prediction from below the BSR caused by overestimation of the reduction in Vs and density, with consequent underestimation of the reduction in $\mathrm{Vp}$ in the presence of free gas (Figure 12). Using the variation in Vs given by the waveform inversion and a smoothly varying density, with DEM-2 for background, provides a lower estimate of hydrate content (up to 3.5\%), even though the fluctuations in Vp are much higher to compensate for the smaller variation in density and Vs across each reflector. One of the reasons for this is that the average values of $\mathrm{Vp}$ in the region above the BSR are higher in the inversion that used DEM-1. The inversion in which density is tied to Vp by Hamilton's relationship yields layer-by-layer variations in $\mathrm{Vp}$ of $60-180 \mathrm{~m} / \mathrm{s}$, equivalent to a variation in hydrate content of $2-9 \%$ for the frame-only model. A smoother density curve yields layer-bylayer variations in $\mathrm{Vp}$ of $80-240 \mathrm{~m} / \mathrm{s}$. The larger variations are sufficiently great to be caused by the juxtaposition of layers containing hydrate with those containing no hydrate, but such an interpretation overlooks the contrast in acoustic impedance between the layers, caused by difference in lithology, that makes the layer boundaries seismically visible in the absence of hydrate.

The higher resolution of the waveform inversion makes plainer the uncertainties in the estimation of hydrate content that arise from the lack of knowledge of the detailed variation in lithology. We cannot, without detailed control on lithology from a borehole, determine whether individual layers with higher velocity have higher hydrate content than those with lower velocity or whether the hydrate content in the layers with higher velocity overestimated, because they already have a higher velocity than adjacent layers. With seismic techniques alone, we can only estimate with any confidence the average hydrate content of broad intervals containing more than one layer, not only because of the uncertainty in the layer-by-layer variation in 
lithology, but also because of the negative correlation in the errors of estimation of velocity between adjacent layers. (Underestimation/overestimation of velocity in a layer causes overestimation/underestimation of velocity in the layer immediately beneath it.)

\subsection{Inversion for $Q p$ and $Q s$ and the effect of hydrate on attenuation}

Quality factor was calculated using a tomographic inversion algorithm (Rossi et al., 2007) based on the frequency-shift method of Quan and Harris (1997). The algorithm used to estimate attenuation relates changes in the centroid frequency of the spectrum of the reflection seismic wavelet to the quality factor of the layer separating the two reflections. A linear integral along each ray path through the tomographic model was performed to calculate the total attenuation and resulting shift in the centroid frequency of the wavelet predicted by the tomographic model to match that shown by the reflected wavelet in the data. As in velocity tomography, each value of Q shown is effectively the average obtained for all the rays passing through each cell of the model. While the frequency-shift method provides good vertical resolution of the variation of $\mathrm{Q}$, each measurement is prone to error because of the short length of the window over which the amplitude/frequency spectrum of the wavelet is calculated $(16 \mathrm{~ms}$ for $P$ wavelets and $30 \mathrm{~ms}$ for $S$ wavelets). For the attenuation tomography, the number of rays per cell was between 300 and 7000.

[Figure 13]

Inversion for the quality factor of $P$ waves $\left(\mathrm{Q}_{\mathrm{p}}\right)$ (Rossi et al., 2007) shows an increase from about 65 just beneath the seabed to about 200 just above the BSR, followed by a decrease downward across the BSR from about 200 to about 60 , which is consistent with the presence of free gas in the zone beneath the BSR (Figure 13). Some of the layers in the free-gas zone show Qp as low as 40, and others are as high as 100. Qp in the 30-m-thick zone just above the BSR is about 60 (30\%) higher than in the two layers above it. The increase in Qp above the BSR is not 
accompanied by an increase in Qs, which varies little with depth below $40 \mathrm{~m}$, lying in the range 46 to 58 to a depth of $270 \mathrm{~m}$, from where it progressively increases with depth.

From the association of highest Qp with the zone in which, from the locally increased Vp, hydrate concentration is likely to be greatest one might expect the increase in elastic modulii caused by hydrate would also lead to an increase in Q, but this is contrary to the observations of Guerin et al (1999), Guerin and Goldberg (2002) and Matsushima (2005) that Qp is inversely dependent upon hydrate content at sonic frequencies $(10-25 \mathrm{kHz})$. It is consistent, however, with the positive correlation between increased hydrate content and higher Qp obtained at 'seismic' frequencies (30-110 Hz) from VSPs offshore Tokai, Japan (Matsushima, 2006). Consequently, it could be suggested that the attenuation mechanism of squirt-flow within the hydrate matrix proposed by Chand and Minshull (2004) or the combination of frictional and squirt-flow mechanisms proposed by Guerin and Goldberg (2005), both based on data from sonic logs, might not be expected to produce significant attenuation at lower, seismic frequencies This would be consistent with the attenuation model of Pride et al. (2004), which predicts that squirt flow is only important at ultrasonic frequencies and that effects of mesoscale features, larger than pores but smaller than the seismic wavelength, govern attenuation at seismic frequencies. At the Mallik Research Well, Mackenzie Delta, Canada, however, results from crosshole tomography in the frequency range 100-500 Hz (Pratt et al., 2005) are in accord with the sonic log results of Guerin and Goldberg (2002) and, although it has been shown by Zanoth et al. (2007) that leaky-mode losses from the higher velocity layers containing hydrate contribute to their apparently low Qp in the results from crosshole tomography, the results from a zero-offset VSP in the frequency range 10-200 Hz (Bellefleur et al., 2007) also show lower Qp in the zones containing hydrate than in the intervening hydrate-free sediment. At N Svalbard, the invariance or slight decrease of Qs where Qp increases in the zone where hydrate is suspected is difficult to explain. If the normal, hydrate-free increases in both Qp and Qs with depth were greater than the measured trends, Qs more so than Qp, then the behaviour of Qp and Qs might be consistent 
with the prediction of model of Guerin and Goldberg (2005) that the reduction in Qs caused by hydrate is greater than that of Qp at seismic frequencies. If this were the case, then we should expect Qs to increase strongly with depth beneath the BSR, where hydrate is absent, but it does not.

At present, there is sufficient uncertainty over the attenuation mechanisms that operate in normal sedimentary rocks (Both squirt flow and mesoscale mechanisms fit the experimental results of Batzle et al. (2006) over a wide range of frequencies.) to make the interpretation of the observed variation of $\mathrm{Q}$ at seismic frequencies at NW Svalbard uncertain in respect of the effect of hydrate on attenuation. Experimental studies by Priest et al. (2006) with a resonant column on the effect of hydrate in pure sand on Qp and Qs, in the frequency range 60-460 Hz, showed significant attenuation produced by low saturation of hydrate, peaking between 3 and $5 \%$, saturation and then decreasing with increasing hydrate concentration. They interpreted the peak in attenuation to be caused by the enhancement of the effect of squirt flow through pore throats by the growth of hydrate at grain contacts, which is subdued as hydrate forms a more continuous rind around the grains, restricting the squirt flow. A possible contributory reason for the difference between the results from Svalbard and those from Mallik and from laboratory experiments, such as those of Priest et al., is that the Mallik and experimental results were obtained in silty/sandy lithologies in which the hydrate was distributed through the pores of the sediment, whereas the sediment at Svalbard is predominantly fine grained and clay rich and the hydrate maybe predominantly fracture-filling. X-ray images have revealed hydrate filling many fine cracks in cores of fine-grained sediment from offshore India, preserved at in-situ pressure (Schultheiss et al., 2006). What would be the appropriate model for the effect on Q of hydrate filling cracks? Current models for the effect of cracks on attenuation have cracks filled with liquid or gas (e.g. Chapman, 2003), which have smaller elastic modulii than the sediment containing the fractures, but for the case of hydrate filling the cracks the elastic modulii of the crack fill would be larger. 


\section{Storegga}

The site at Storegga lies on the northern margin of the Storegga slide (Figure 14). A BSR is developed discontinuously over a wide area and is restricted in its occurrence to the hemipelagic and contourite sediments of the glacial-interglacial Naust formation (Bünz et al., 2003). The character of the BSR varies considerably in this area. At some locations, the BSR is a continuous reflection, whereas in others it can hardly be recognised. Commonly, it is represented by changes in the amplitude and, in some cases, the polarity of strata-parallel reflectors. A number of fluid/gas-escape chimneys can be observed on the upper slope area, most of which seem to originate beneath the BSR. Methane hydrate has been sampled from pockmarks at the tops of similar chimneys lying 30-35 km to the east (Ivanov et al., 2007). At this site, a rectangular array of 21 OBS was deployed at the same position as a previous survey with an ocean-bottom cable (Andreassen et al., 2003; Bünz and Mienert, 2004), at the centre of which lies a geotechnical borehole that penetrates beneath the depth of the BSR (Bünz and Mienert, 2004). Samples of hydrate were not, however, successfully recovered from the borehole (Mienert and Bryn, 1997). The OBS array had a similar pattern of shot lines, and the data from it were analysed using the same techniques, as described for the NW Svalbard site. In addition, a 3D high-resolution reflection survey was conducted over the area of the site (Nouzé et al., 2004). Extending up slope from the rectangular array, a linear array of OBS was deployed to explore the lateral variation in the character of the BSR.

[Figure 14]

As can be seen in the seismic section running SW-NE through the whole survey area, the character of the BSR changes laterally, and the BSR is locally absent from the centre of the line (Figure 15). Down slope, at the SW end of the line, the BSR is patchily displayed where the base of the hydrate stability field intersects some of the sedimentary layers, but not others. The 
amplitude of some of the reflections from these layers changes markedly across the BSR, commonly with an associated change in polarity. Previous work on the data from the oceanbottom cable (Andreassen et al., 2003; Bünz and Mienert, 2004) and from individual OBS with shot lines along strike (Bünz et al., 2005) showed a downward reduction in Vp across the BSR of about $400 \mathrm{~m} / \mathrm{s}$, with no decrease in Vs. The results from HYDRATECH are in accord with these observations, but show that the reduction in $\mathrm{Vp}$ is laterally variable, dependent upon which layers are intersected by the BSR. It is evident that some layers, presumably with higher permeability, are hosts to a higher free-gas content below the BSR, and possibly a higher hydrate content above the BSR, causing a greater change in Vp where they are intersected by the BSR than layers nearby with a lower gas content. In the central part of the seismic transect, the BSR is not visible, but the presence of the base of the hydrate stability field is indicated by a lateral change in amplitude of one of the more prominent reflectors at $1.55 \mathrm{~s}$ twt. Upslope from the central part of the seismic transect, between $1.45 \mathrm{~s}$ and $1.38 \mathrm{~s}$, the BSR is exhibited as a prominent, continuous reflector with negative polarity.

[Figure 15]

[Figure 16]

Travel-time inversion of the OBS data shows that a zone of markedly reduced Vp underlies the BSR near the top of the slope (Figure 16). The reduction in velocity is about $400 \mathrm{~m} / \mathrm{s}$, although this is not well determined, because the layer is thin. Above the BSR, Vs is higher in a 50-m thick zone above it than in the next $200 \mathrm{~m}$ below it (Figure 17). This increase is probably caused by hydrate, and is associated with a local increase in $\mathrm{Vp}$. The section also shows reductions in $\mathrm{Vp}$ in deeper layers, indicating widespread, stratigraphically controlled invasion of the region beneath the BSR by free gas. The interpretation that these low velocity zones are caused by free gas is supported by the absence of any concomitant reduction in Vs (Figure 17). Some of these 
layers, which lie below the BSR, show noticeable lateral variation in Vp. The layer immediately below the low velocity zone underlying the BSR has a lower velocity where it lies beneath the BSR (NE of $11.5 \mathrm{~km}$, Figure 16) than in the region where the layer intersects the BSR and emerges above it (SW of $9 \mathrm{~km}$, Figure 16). This lateral increase in Vp within the same layer is presumably caused by the reduction in the amount of free gas and its possible replacement by hydrate where the layer lies above the base of the hydrate stability field. Leaving aside the locally low values of $\mathrm{Vp}$ associated with gas, the generally low values of $\mathrm{Vp}$ and Vs in the deeper part of this section, suggest that it is under-compacted and over-pressured.

[Figure 17]

The concentration of gas hydrate was calculated for the site of the geotechnical borehole, at the centre of the OBS array, using the DEM model. Variations in porosity and composition with depth, measured from samples taken from the borehole, were used to define the model and predict $\mathrm{Vp}$ as a function of depth in the absence of hydrate. This 'expected' background function of $\mathrm{Vp}$ provided the basis from which to predict the concentration of hydrate present in the pore space that would give the variation of $\mathrm{Vp}$ with depth that was obtained by waveform inversion of the data from OBS 686, close to the borehole site (Figure 18). The predicted concentrations of hydrate range up to $12 \%$ for the frame-only model and up to $20 \%$ for the frame-plus-pore model, apart from a local spike.

[Figure 18]

It is interesting to compare this prediction of hydrate concentration with the values predicted by Bünz et al. (2005) for two locations, separated by about $400 \mathrm{~m}$, close by along the same profile. Using a $\mathrm{Vp} / \mathrm{Vs}$ relationship derived from velocity/depth functions in this area where hydrate was not present, they used Vs to predict the background values of Vp. From the difference 
between these and the measured $\mathrm{Vp}$, they applied the effective-medium method of Helgerud et al. (1999), with the same borehole geotechnical data, to predict the concentration of hydrate. Values of $6 \%$ and $11 \%$ of pore space were obtained for the case where hydrate forms a part of the framework, and $12 \%$ and $21 \%$ for the pore-filling case, in a zone about $50-\mathrm{m}$ thick just above the BSR at the two locations. The differences between the two locations may be as much a consequence of a lack of constraint on the velocity inversions, which are essentially 1D and sample a region much greater in extent than the separation of the two locations, as any lateral variation in hydrate concentration. By deriving the background value of $\mathrm{Vp}$ from $\mathrm{Vs}$, their approach implicitly assumes that Vs is not affected by the presence of hydrate, but, in fact, Vs is affected by hydrate, especially for the framework-forming models (Chand et al., 2006). Consequently, their results are most valid for the pore-filling case, which is their preferred model.

For the prediction of hydrate concentration using the data from OBS 686, the relatively sparse sampling of the borehole, which was not continuously cored, and the problem of extrapolating the properties derived from the samples into the surrounding region sampled by the seismic experiment, have contributed to errors in the background velocity curve. Also, the waveform inversion at OBS 686 used Castagna's relationship for the variation of Vp and Vs in muddy rocks (Castagna et al., 1985) to obtain Vs from Vp rather than the recorded $S$-wave data. In these low-velocity sediments, this tends to overestimate Vs, leading to an overestimate of hydrate concentration. Zillmer et al. (2005), using a formula that assumes that hydrate is pore filling, estimated hydrate concentrations of $5-18 \%$ of pore space between the seabed and the BSR from a function of $\mathrm{Vp}$ with depth that provided optimal 1D Kirchhoff depth migration of the hydrophone data from OBS687. To estimate hydrate concentration, their method used measurements of porosity between 48 and $63 \%$ from core samples from the borehole (reported in Bünz and Mienert, 2004), which were obtained with a technique (measuring dry weight and wet weight) that overestimates porosity in clay-rich sediment. If these porosity values were $4 \%$ 
too high then the predicted hydrate concentration would range from zero at the seabed to $10 \%$ in a zone 200-m thick above the BSR. The three approaches used different background curves, explicitly or implicitly. In summary, it appears that hydrate concentration does not exceed $10 \%$ of pore space in the SW part of the site at Storegga, if the frame-forming model is valid, or 20\% if the pore-filling model is valid.

\section{Discussion and Conclusions}

The principal uncertainty in deriving hydrate concentration from seismic velocity is the lack of knowledge of the appropriate model for the effect of hydrate on the seismic properties of its host sediment. Which is the most appropriate model to use for predicting hydrate content from seismic velocity? It is not intuitively obvious that at very low concentration there is sufficient hydrate to form a connected framework. Yet, the frame-only model, applied using the DEM approach, gave the best predictions of $\mathrm{Vp}$ and $\mathrm{Vs}$ for laboratory experiments with known concentrations of hydrate (Priest et al., 2005a; Priest et al., 2005b; Chand et al., 2006). These experiments showed a particularly rapid rise in both $\mathrm{Vp}$ and $\mathrm{Vs}$ from 0 to $3 \%$ hydrate. The experiments, however, used pure sand, and employed a method to grow the hydrate in the laboratory (Stern et al., 1996) that may concentrate the hydrate at grain contacts, which may make $\mathrm{Vp}$ and $\mathrm{Vs}$ sensitive to low hydrate content by increasing the rigidity of the sediment frame. Furthermore, experimental work by Yun et al. (2005) on unconsolidated sediment containing tetrahydrofuran hydrate indicated that frame forming by hydrate did not have a large effect on seismic velocity until hydrate concentration approaches $40 \%$. The effect of hydrate on velocity is known to depend on the lithology of the host sediment (Chand et al., 2006), and it may also depend upon whether the hydrate grows from methane in solution or from free-gas. The sediment at Svalbard has a high content of clay. Consequently, predictions of hydrate content based solely on the frame-only model are likely to be underestimates. A further complication for the models of the effect of hydrate on seismic properties, which commonly assume pore-scale interactions between hydrate and its host sediment, is that in low- 
permeability, clay-rich sediment, hydrate can occupy fractures and bedding planes (e.g. Schultheiss et al., 2006; Lu et al., 2006; Ivanov et al., 2007), rendering redundant, at least in part, the pore-filling model for the effect of hydrate on velocity for cases where this occurs. At NW Svalbard, Qp showed a positive correlation with the presence of hydrate in the frequency range of the seismic experiments $(20-120 \mathrm{~Hz})$, in contrast with the negative correlation shown by borehole measurements made at sonic frequencies $(10-25 \mathrm{kHz})$ (e.g. Guerin and Goldberg, 2002), but consistent with the results from VSPs at seismic frequencies $(30-110 \mathrm{~Hz})$, conducted offshore Japan (Matsushima, 2006). Qs, however, shows no obvious correlation with hydrate content derived from Vp and Vs. It appears, from the above, that a combination of pore filling and frame forming provides a general model for the manner in which hydrate occurs in sediment and affects the seismic properties, but the relative importance of pore filling versus frame forming, depending the degree of hydrate saturation, the lithology of the host sediment and the presence or absence of mesoscale fractures, is still not well determined. The resolution of these issues waits upon further progress with laboratory and in-situ investigations.

The 2D and 3D inversion of high-resolution data sets from seabed arrays of four-component OBS with dense patterns of shots, enabled the definition of $\mathrm{Vp}$ and $\mathrm{Vs}$ in the region of occurrence of hydrate with sufficient accuracy to discriminate variations of hydrate concentration greater than $3 \%$ to $7 \%$ of pore space, depending on the model for the effect of hydrate on seismic velocity, with a high degree of confidence. With waveform inversion, the differences in the seismic velocities of inter-reflector intervals can be resolved, but, without knowledge of the local differences in the lithology of the layers, these inter-layer variations in velocity cannot be interpreted in terms of the variation in hydrate content. In this investigation, an interval of about $20-\mathrm{m}$ thickness (equivalent to between 2 and 5 layers in the model for waveform inversion) was the smallest within which one could sensibly estimate the hydrate content. This is a consequence of the error in determining the average velocity of the interval (about $2.5 \%$, or $\pm 45 \mathrm{~m} / \mathrm{s}$ at $95 \%$ confidence) and the extent to which local lithology-dependent 
variations in velocity average out, relative to the effect of hydrate on velocity. If lithological layering much thinner than 20-m thickness controls hydrate content, then hydrate concentrations within layers could significantly exceed or fall below the average values derived from seismic data. It appears unlikely that this occurs to any great extent at N Svalbard, however, because the amplitudes of reflectors in the gas hydrate stability zone do not vary greatly as the reflectors progressively diverge from the BSR, traversing zones of decreasing estimated hydrate concentration, as the BSR becomes deeper downslope (Figure 2.)

With appropriate control from nearby boreholes to provide physical properties and porosity/depth behaviour, or from Vp and Vs functions of depth at nearby control sites with the same lithology but without hydrate, it is possible to define Vp and Vs background functions and hence the velocity anomalies caused by hydrate. With these controls, the hydrate content can be derived to within a few percent of pore space if the appropriate model for the effect of hydrate content upon velocity is known. In situations where this control is not available, however, the uncertainty in the background velocity is a major cause of uncertainty in estimating the amount of hydrate present, such that the presence of hydrate at concentrations of up to about $10 \%$ or more of pore space, depending on the degree to which hydrate is frame-forming or pore-filling, could either be overlooked or erroneously predicted. In these cases, the presence of a BSR is the most reliable indicator of the presence of hydrate, although it provides little to no information on the amount of hydrate that is present.

The work reported in this paper has demonstrated the value of using 4-component seismic recorders on the seabed for provision of well-determined seismic velocity at high resolution with 3D control and for the measurement of $S$-wave properties, which provide additional constraints upon the predicted value of hydrate concentration through models of the effect of hydrate on the seismic properties of the sediment in which hydrate occurs. It has illustrated the limitations of seismic methods for predicting hydrate concentration in the absence of local 
borehole control, even when self-consistent approaches are applied to the data, with reasonable assumptions concerning lithology and the background values of physical properties.

\section{Acknowledgements}

The HYDRATECH project (Techniques for the Quantification of Methane Hydrate in European Continental Margins), which brought together nine European groups undertaking research on a number of aspects of hydrate occurrence and formation to examine the viability of seismic techniques in the detection and quantification of methane hydrate in continental margins, was funded by the European Commission under FP5 contract no. EVK3-CT-2000-00043, and was one of the OMARC cluster of projects. We acknowledge the constructive comments made by Debbie Hutchinson and two other, anonymous, reviewers on the first draft of this paper, which helped us improve the clarity of its presentation. 


\section{References}

Andreassen, K., Berteussen, K.A., Sognnes, H., Henneberg, K., Langhammer, J., Mienert J., 2003. Multicomponent ocean bottom cable data in gas hydrate investigations offshore Norway. Journal of Geophysical Research, 108, 2399. doi:10.1029/2002JB00245.

Bellefleur, G., Riedel, M., Brent, T., Wright, F., Dallimore, S.R. 2007. Implication of seismic attenuation for gas hydrate resource characterisation, Mallik, Mackenzie Delta, Canada. Journal of Geophysical Research. 112, B10311, doi:10.1029/2007JB004976.

Bünz, S., Mienert, J., Berndt, C., 2003. Geological controls on the Storegga gas-hydrate system of the mid-Norwegian continental margin. Earth Planetary Science Letters, 209, 291-307.

Bünz, S., Mienert, J., 2004. Acoustic imaging of gas hydrate and free gas at the Storegga Slide. Journal of Geophysical Research. 109, B04102, doi:10.1029/2003JB002863.

Bünz, S., Mienert, J., Vanneste, M., Andreassen, K., 2005. Gas hydrates at the Storegga Slide: Constraints from an analysis of multi-component, wide-angle seismic data. Geophysics, 70(5), B19-34.

Carcione, J.M., Gei, D., Rossi, G., Madrussani, G., 2005. Estimation of gas-hydrate concentration and free-gas saturation at the Norwegian-Svalbard continental margin. Geophysical Prospecting, 53, 803-810.

Castagna, L.P., Batzle, M.L., Eastwood, R.L., 1985. Relationships between compressional- and shear-wave velocities in clastic silicate rocks. Geophysics, 50(4), 571-581.

Chand, S., Minshull, T.A., 2004. The effect of hydrate content on seismic attenuation - a Case study from Mallik 2L-38 well data, MacKenzie Delta, Canada. Geophysical Research Letters, 31, L14609, doi:10.1029/2004GL020292.

Chand, S., Minshull, T.A., Gei, D., Carcione, J., 2004. Gas hydrate quantification through effective medium theories - a comparison. Geophysical Journal International, 159, 573590.

Chand, S., Minshull, T.A., Priest, J.A., Best, A.I., Clayton, C.R.I and Waite, W.F., 2006. An 
effective medium inversion algorithm for gas hydrate quantification and its application to laboratory and borehole measurements of gas hydrate sediments, Geophysical Journal International, 166, 543-552.

Eiken, O., Hinz, K., 1993. Contourites in the Fram Strait. Sedimentary Geology, 82, 15-32.

Guerin, G., Goldberg, D., 2002. Sonic waveform attenuation in gas hydrate-bearing sediments from the JAPEX/JNOC/GSC Mallik 2L-38 research well, Mackenzie Delta, Canada, Journal of Geophysical Research, 107(B5), 2088, doi:10.1029/2001JB000556.

Guerin, G., Goldberg D. 2005, Modeling of acoustic wave dissipation in gas hydrate-bearing sediments, Geochemistry Geophysics Geosystems, 6, Q07010, doi:10.1029/2005GC000918.

Guerin, G., Goldberg, D., Meltser A. 1999. Characterization of in situ elastic properties of gas hydrate-bearing sediments on the Blake Ridge, Journal of Geophysical Research, 104, $17,781-17,796$.

Haacke, R.R., Westbrook, G.K., Peacock, S., Long, C., 2005. Seismic anisotropy from a marine gas hydrate system west of Svalbard. Proceedings of $5^{\text {th }}$ International Conference on Gas Hydrates, 2005, 621-630.

Haacke, R. R., Westbrook, G. K., 2006. A fast, robust method for detecting and characterizing azimuthal anisotropy with marine $P S$ converted waves, and its application to the west Svalbard continental slope. Geophysical Journal International, 167, 1402-1412, doi:10.1111/j.1365-246X.2006.03186.

Hamilton, E.L., 1978. Sound velocity-density relations in sea-floor sediments and rocks. Journal of the Acoustical Society of America, 63, 366-377.

Hamilton, E.L, 1980. Geoacoustic modeling of the sea floor. Journal of the Acoustical Society of America, 68, 1313-1340.

Helgerud, M.B., Dvorkin, J., Nur, A., Sakai, A., Collett, T.S., 1999. Elastic-wave velocity in marine sediments with gas hydrates: Effective medium modelling, Geophysical Research Letters, 26, 2021-2024. 
Ivanov, M., Westbrook, G.K., Blinova, V., Kozlova, E., Mazzini, A., Nouzé, H., Minshull, T.A. 2007. First sampling of gas hydrate from the Vöring Plateau, Eos, Transactions of the American Geophysical Union, 88(19), 209-212.

Jansen, E., Raymo, M.E., Blum, P., and Shipboard Scientific Party, 1996. Ocean Drilling Program. Site 986. Proceedings of the Ocean Drilling Program, Initial Reports 162.

Lu, H., Moudrakovski, I.I., Schicks, J., Ripmeester, J.A., Zhang, M. 2006. The characteristics of gas hydrates recovered from Northern Cascadia margin by IODP Expedition 311, Eos Transactions. AGU, 87(52), Fall Meeting Supplement, Abstract OS11E-08.

Matsushima, J., 2005. Attenuation measurements from sonic waveform logs in methane hydrate-bearing sediments at the Nankai Trough exploratory well off Tokai, central Japan, Geophysical Research Letters, 32, L03306, doi:10.1029/2004GL021786.

Matsushima, J., 2006. Seismic attenuation in methane-hydrate-bearing sediments: vertical seismic profiling data from the Nankai Trough exploratory well, offshore Tokai, central Japan, Journal of Geophysical Research, 111, B10101, doi:10.1029/2005JB004031.

Mavko, G., Mukerji, T., Dvorkin, J. 1998. The Rock Physics Handbook: Tools for Seismic Analysis in Porous Media. Cambridge University Press.

Mienert, J., Bryn, P. 1997. Gas hydrate drilling conducted on the European margin, Eos, Transactions American Geophysical Union, 78(49), 567-567.

Minshull, T.A., Singh, S.C., Westbrook, G.K., 1994. Seismic velocity structure of a gas hydrate reflector offshore western Colombia from full waveform inversion, Journal of Geophysical Research, 99, 4715-4734.

Nolet, G., Dorman, J., R., 1996 Waveform Analysis of Scholte Modes in Ocean Sediment Layers, Geophysical Journal International, 125, 385-396.

Nouzé, H., Contrucci, I., Foucher, J.P., Marsett, B., Thomas, Y., Théreau, I., Normand, A., Le Drezen, E., Didailler, S., Regnault, J.P., Le Conte, S., Guidard, S., Lekens, W., Dean, S., Throo, A., 2004. Premiers résultats d'une étude géophysique sur le flanc nord des 
glissements de Storegga. First results of a geophysical survey on the northern flank of the Storegga slides, Comptes Rendus Geoscience, 336, 579-585.

Posewang, J., Mienert, J., 1999. High-resolution seismic studies of gas hydrates west of Svalbard, Geo-Marine Letters, 19(1-2), 150-156.

Pratt, R.G., Hou, F., Bauer, K., Weber, M. 2005. Waveform tomography images of velocity and inelastic attenuation from the Mallik 2002 cross-hole seismic surveys, in Scientific Results from the Mallik 2002 Gas Hydrate Production Research Well Program, Mackenzie Delta, Northwest Territories, Canada, (editors S.R. Dallimore and T.S. Collett), Bulletin of the Geological Survey of Canada, 585, 14pp.

Priest, J.A., Best, A.I., Clayton, C.R.I., 2005a. A laboratory investigation into the seismic velocities of methane gas hydrate-bearing sand. Journal of Geophysical Research, 110, B04102, doi:10.1029/2004JB003259.

Priest, J.A., Best, A.I., Clayton, C.R.I., 2006. Attenuation of seismic waves in methane gas hydrate-bearing sand. Geophysical Journal International, 164, 149-159.

Priest, J., Best, A., Clayton, C., Watson, E, 2005b. Seismic properties of methane gas hydratebearing sand. Proceedings of $5^{\text {th }}$ International Conference on Gas Hydrates, 2005, pp. 440447.

Quan, Y., Harris J. M. 1997. Seismic attenuation tomography using the frequency shift method. Geophysics, 62, 895-905.

Rossi, G., Vesnaver, A., 2001. Joint 3D traveltime inversion of P, S and converted waves. Journal of Computational Acoustics, 9, 1407-1416.

Rossi, G., Madrussani, G., Gei, D., Böhm, G., Camerlenghi, A. 2005. Velocity and attenuation 3D tomography for gas-hydrates studies: the NW offshore Svalbard case, Proceedings of $5^{\text {th }}$ International Conference on Gas Hydrates, 2005, 677-682.

Rossi, G., Gei, D., Böhm, G., Madrussani, G., Carcione, J.M. 2007. Attenuation tomography: an application to gas-hydrate and free-gas detection. Geophysical Prospecting, 55, 655-669.

Schultheiss, P., Holland, M., Roberts, J., Druce, M., IODP Expedition 311 Shipboard Scientific 
Party, NGHP Expedition 1 Shipboard Scientific Party, 2006. Gas Hydrate Investigations Using Pressure Core Analysis: Current Practice, Eos Transactions. AGU, 87(52), Fall Meeting Supplement, Abstract OS11E-03.

Shipley, T.H., Houston, M.H., Buffler, R.T., Shaub, F.J., McMillen, K.J., Ladd, J.W., Worzel, J.L., 1979. Seismic reflection evidence for the widespread occurrence of possible gashydrate horizons on continental slopes and rises. American Association of Petroleum Geologists Bulletin, 63, 2204-2213.

Singh, S.C., Minshull, T.A., Spence, G.D., 1993. Velocity structure of a gas hydrate reflector. Science, 260, 204-207.

Stern, L.A., Kirby, S.H. \& Durham, W.B., 1996. Peculiarities of methane clathrate hydrate formation and solid state deformation, including possible super heating of water ice, Science, 273, 10299-10311.

Taylor, D.B., 1992. Aniseis manual, Macroc Ltd./Applied Geophysical Software, inc., Edinburgh.

Vesnaver A., Böhm G. 2000. Staggered or adapted grids for seismic tomography? The Leading Edge, 19, 944-950.

Vanneste, M., Guidard, S., Mienert, J., 2005. Arctic Gas Hydrate Provinces along the Western Svalbard Continental Margin. In:. Wandås, B.T.G., Eide. E., Gradstein, F., Nystuen, J.P., editors. Onshore - offshore relationships on the North Atlantic Margin. Norwegian Petroleum Society (NPF), Special Publication 12. Elsevier, Amsterdam, 271-284.

Westbrook, G.K., Long C., Peacock, S., Haacke, R., Reston, T., Zillmer, M., Flueh, E., Foucher, J.P., Nouzé, H., Contrucci, I., Klingelhoefer, F., Best, A.I., Priest, J.A., Camerlenghi, A., Carcione, J., Rossi, G., Madrussani, G., Gei, D., Mienert, J., Vanneste, M., Buenz, S., Hetland, S., Larsen, R., Habetinova, E., Minshull, T.A., Chand, S., Clayton, C.R.I., Dean, S. 2004. Final Report of Techniques for the Quantification of Methane Hydrate in European Continental Margins - HYDRATECH. 2004, with annexes, available from the project's web site at http://www.hydratech.bham.ac.uk/ 
Westbrook, G.K., Buenz, S., Camerlenghi, A., Carcione, J., Chand, S., Dean, S., Foucher, J-P, Flueh, E. Gei, D., Haacke, R., Klingelhoefer, F., Long, C. Madrussani, G. Mienert, J., Minshull, T.A., Nouzé, H., Peacock, S, Rossi, G., Roux, E., Reston, T., Vanneste, M., Zillmer, M. 2005. Measurement of $P$ - and $S$-wave velocities, and the estimation of hydrate concentration at sites in the continental margin of Svalbard and the Storegga region of Norway. Proceedings of $5^{\text {th }}$ International Conference on Gas Hydrates, 2005, 726-735.

Yun, T.S., Francisca, F.M. Santamarina, J.C., Ruppel, C. 2005. Compressional and shear wave velocities in uncemented sediment containing gas hydrate, Geophysical Research Letters, 32, L10609, doi:10.1029/2005GL022607.

Zanoth, S.R., Saenger, E.H., Krüger, O.S., Shapiro, S.A. 2007. Leaky mode: A mechanism of horizontal seismic attenuation in a gas-hydrate-bearing sediment, Geophysics, 72(5), E159-E163, doi:10.1190/1.2750375

Zelt, C.A., Smith, R.B., 1992. Seismic traveltime inversion for a 2-D crustal velocity structure. Geophysical Journal International, 108, 16-34.

Zillmer, M., Reston, T., Leythaeuser, T. Flueh, E.R. 2005. Imaging and quantification of gas hydrate and free gas at the Storegga slide offshore Norway. Geophysical Research Letters, 32, L04308, doi:10.1029/2004GL021535. 


\section{Appendix 1: Errors in model velocities from 2D ray-tracing inversion of travel times}

The approach used to evaluate errors in velocity was to vary the velocities of the layers in the model from their best-fit values until the misfit function (Chi square) between the observed and model travel times was significantly different from its best fit value at the $95 \%$ confidence level. The uncertainty in the velocity of each layer of the velocity model was determined, by iteratively changing its velocity proportionally from the values obtained for the optimal model, adjusting the shape of the layer for each increment of velocity to obtain the best fit Chi-square value, and testing each of these Chi-square values against the Chi-square value for the original best-fit velocity to find the velocity that is significantly different from the best-fit velocity at the 95\% confidence level. This was achieved using the $\mathrm{F}$ test (variance-ratio test) to determine from their corresponding Chi-square values whether two models are significantly different at the chosen confidence level. A change in the velocity and shape of a layer, however, affects the velocities obtained for all layers in the model beneath it. These were also evaluated by inverting the model for the velocities of the deeper layers, while keeping the velocity and shape of the target layer fixed at the values for the $95 \%$ confidence limit. Most strongly affected is the layer immediately beneath, which shares a common boundary with the layer in which the velocity is changed. The velocities obtained for layers deeper than this, in models with the fairly simple layer geometry of the sites of the seismic experiments, are not affected significantly by the velocity change in the target layer. Nearly all the effect upon travel times to deeper layers is compensated by the changes in velocity and thickness of the layer immediately beneath the target layer. Consequently, the principal factors affecting the uncertainty in the value derived for seismic velocity in a layer are the uncertainties in the shapes of its lower and upper boundaries and the uncertainty in the velocity of the layer immediately above it.

The three layers above and three layers below the BSR in the model sections from Svalbard line 4 and Storegga line B1 were investigated for velocity uncertainty, by deriving the proportionate 
change in velocity needed to bring the misfit function for each layer to the $95 \%$ confidence bound and the change in velocity that this induced in its subjacent layer, from an optimal raytracing solution for the modified velocities of both layers and the shape of their common boundary. The resultant estimate of the error in velocity in each layer is the combination of the error arising from the fit of the reflections from its bottom boundary and the change in velocity produced by the error in the velocity of the overlying layer.

\section{N Svalbard Section 4}

Layer 6

Layer 7

Layer 8 - part of stratigraphic layer above BSR

Layer 9 - part of stratigraphic layer below BSR

Layer 10

Layer 11

\begin{tabular}{|c|c|}
\hline $\begin{array}{l}\text { Average } \\
\text { Best-fit } \\
\text { velocity } \\
(\mathrm{km} / \mathrm{s})\end{array}$ & $\begin{array}{l}\text { Error for } \\
\text { single laye } \\
\text { (\% error a } \\
95 \% \text { conf.) }\end{array}$ \\
\hline
\end{tabular}

\begin{tabular}{|l|l|l|l|}
\hline 1.71 & 0.94 & -0.82 & 1.25 \\
\hline 1.78 & 1.34 & -0.59 & 1.46 \\
\hline 1.81 & 2.82 & -1.55 & 3.22 \\
\hline 1.52 & 3.70 & -3.45 & 5.06 \\
\hline 1.60 & 3.10 & -1.94 & 3.66 \\
\hline 1.66 & 3.45 & -5.06 & 6.12 \\
\hline
\end{tabular}

\section{Storegga Line B1}

Layer 7

Layer 8

Layer 9 - stratigraphic layer above BSR

Layer 10 - stratigraphic layer below BSR

Layer 11

Layer 12

Average Effect of error Effect of error Combined \% Best-fit in overlying in overlying error for layer velocity layer (\% error layer (\% error at 95\% conf. ( $\mathrm{km} / \mathrm{s}) \quad$ at $95 \%$ conf.) at $95 \%$ conf.)

\begin{tabular}{|l|l|l|l|}
\hline 1.63 & 1.67 & \multicolumn{2}{|l}{} \\
\hline 1.68 & 0.85 & -1.55 & 1.77 \\
\hline 1.70 & 0.84 & -0.63 & 1.05 \\
\hline 1.30 & 8.50 & -1.44 & 8.62 \\
\hline 1.71 & 1.52 & -0.78 & 1.71 \\
\hline 1.70 & 2.94 & -1.41 & 3.26 \\
\hline
\end{tabular}


From the tables, it is noticeable that the errors for the deeper layers, with lower signal-to-noise and lower dominant frequency, are greater. Also, the error varies inversely with the thickness of the layers. The thin gas-charged layer beneath the BSR (Layer 10) in the Storegga section has a noticeably higher error in its velocity than the other layers. The errors are conservative, because the model is quite smoothly varying, constraining it from sharp lateral changes in velocity and thickness of layers, except where layers were offset by faults.

Appendix 2: Properties of the 1D model used to generate the synthetic seismic section of

Figure 5.

\begin{tabular}{|c|c|c|c|}
\hline Thickness $\mathrm{m}$ & Density $\mathrm{kg} / \mathrm{m}^{3}$ & $\mathrm{Vp} \mathrm{m} / \mathrm{s}$ & $\mathrm{Vs} \mathrm{m} / \mathrm{s}$ \\
\hline 1394 & 1010 & 1470 & 0 \\
\hline 10 & 1541 & 1512 & 103 \\
\hline 12 & 1548 & 1516 & 165 \\
\hline 17 & 1569 & 1521 & 185 \\
\hline 10 & 1588 & 1571 & 195 \\
\hline 35 & 1620 & 1582 & 219 \\
\hline 25 & 1660 & 1641 & 255 \\
\hline 17 & 1688 & 1702 & 366 \\
\hline 44 & 1726 & 1733 & 377 \\
\hline 28 & 1771 & 1784 & 445 \\
\hline 3 & 1789 & 1821 & 469 \\
\hline 24 & 1805 & 1537 & 451 \\
\hline 35 & 1838 & 1567 & 482 \\
\hline 15 & 1866 & 1648 & 537 \\
\hline 32 & 1891 & 1706 & 585 \\
\hline 21 & 1919 & 1726 & 594 \\
\hline 19 & 1940 & 1768 & 617 \\
\hline 50 & 1974 & 1847 & 659 \\
\hline 88 & 2038 & 1922 & 694 \\
\hline
\end{tabular}




\section{Figure Captions}

Figure 1: a) Map of the western continental margin of Svalbard, showing the two sites of HYDRATECH seismic experiments and ODP drill site 986. b) Pattern of shot lines and array of OBS at the NW site. Nominal OBS spacing is $400 \mathrm{~m}$. Line spacing is $200 \mathrm{~m}$. Shot spacing is $\leq 25 \mathrm{~m}$. Heavy line shows the location of the seismic section illustrated in Figure 2.

Figure 2: Seismic section from shot line 4 at the NW site (shown as heavy line in Figure 1b). The positions of five OBS from the array shown in Fig. 1b, situated on or close to the line are shown. A BSR (bottom-simulating reflector) cuts the stratal reflectors about $300 \mathrm{~ms}$ below the seabed.

Figure 3: Grey-scale display of a gather of records from the hydrophone channel of OBS 639 at the NW Svalbard Site, showing the reflected $P$-wave arrivals. (See Fig. 2 for the position of OBS 639.) The plot has been reduced to flatten a reflector in the centre of the figure by applying a time shift to each trace that is equal to the difference between $1.25 \mathrm{~s}$ and the travel time predicted for a reflector that has $1.25 \mathrm{~s}$ travel time at zero offset. The position of the OBS is at the minimum travel time for the direct wave. Note the increase in amplitude of the BSR at far offsets and its cross-cutting relationship to the other reflectors.

Figure 4: Grey-scale display of a gather of records of the radial component (vector combination of the two horizontal geophone records in the direction of the shot) from OBS 639 at the NW Svalbard Site, showing the $P-S$ converted waves, which have a lower dominant frequency than the $P$ waves. The plot is reduced for seawater velocity at the seabed, which flattens the direct arrival. 
Figure 5: Synthetic seismic section generated with the reflectivity technique (Taylor, 1992) from a 1D model based on the variation of $\mathrm{Vp}$ and $\mathrm{Vs}$ with depth at the position of OBS 639 derived from $2 \mathrm{D}$ ray-trace inversion. The properties of the model are given in Appendix 2. As discussed in the text, Vs in the model just beneath the seabed, although lower than that derived by inversion for an 84-m-thick layer is higher than the real value, because the synthetic seismic section shows reflected $\mathrm{S}$ waves generated by PS conversion at the seabed that in the data are too weak to be seen (Figure 4). The synthetic section only shows seismic phases generated by the model, which represents only some of the reflectors, and so is sparse in comparison with the real section.

Figure 6: Comparison of the $P$-wave velocity models obtained from three different inversion techniques. $\mathrm{Vp}$ as functions of depth from the 2D ray-traced and 3D tomographic models are taken at the positions of OBS in the array. Result of 1D waveform inversion is for data from the strike-parallel shot line through OBS 639. The uppermost and lowermost parts of the tomographic model have fewer layers than the 2D ray-trace models. The empirical Vpdepth curve for terrigenous sediment from Hamilton (1980) is shown for comparison.

Figure 7: Sections through the tomographically derived 3D Vp model for the NW Svalbard site. The horizontal size of the "cube" is 6 x $6 \mathrm{~km}$. Its thickness is $0.7 \mathrm{~km}$. The view is from the SW.

Figure 8: Comparison of $S$-wave velocity (Vs) as a function of depth at each OBS from 2D raytraced travel-time inversion with that from 3D tomographic inversion at OBS 644, NW Svalbard. The tomographic model has fewer layers in the upper and lower parts of the model. Both models lack sufficient layers with clear $P-S$ arrivals in the uppermost $80 \mathrm{~m}$ to be able to define the variation in Vs with depth properly. The blue curve shows a likely 
variation of Vs, based on results from similar sediment sequences elsewhere (e.g. Nolet and Dorman (1966)), that satisfies the travel times for the shallowest $P-S$ converting interface.

Figure 9: Comparison of estimated hydrate concentration derived from the same ray-tracingderived variation of $\mathrm{Vp}$ and $\mathrm{Vs}$ with depth at the position of OBS 639, using different background velocity curves for the expected variation of velocity with depth in the absence of hydrate. The values of hydrate concentration were calculated from the average Vs and Vp for each layer (shown by the crosses and diamonds on the Vs and Vp curves respectively). The blue section of the plot indicates the region between the BSR and the seabed. A differential effective medium model in which the hydrate forms a connected framework (frame-only model) gives lower values of hydrate concentration. A differential effective medium model in which hydrate partially fills pore space as well as forming a framework (frame-plus-pore model) gives higher predicted values of hydrate concentration.

Figure 10: Concentration of hydrate in pore space, derived from the variation in $\mathrm{Vp}$ and $\mathrm{Vs}$ in a 2D model along shot line 4 obtained by travel-time inversion. The differential effective medium frame-only model of Chand et al. (2006) was used to estimate hydrate concentration. The dark blue line shows the position of the BSR.

Figure 11: Concentration of hydrate above the BSR and free gas below the BSR, predicted with the Bioot-type model of Carcione et al. (2005), derived from a NW-SE section of the tomographic Vp model through the centre of the OBS array at the NW Svalbard site.

Figure 12: LEFT: Vs and Vp derived from waveform inversion at OBS 639. Vs1 is derived from Vp1 via Castagna's relationship (red curve) and Vs2 and Vp2 are both obtained from the inversion (green curve). Also shown are the background values of $\mathrm{Vp}$ and $\mathrm{Vs}$ in the absence of hydrate predicted by the differential effective medium model (DEM-1, used 
with the red curve, and DEM-2 used with the green curve). The values of Vp and Vs obtained from the ray-traced model are shown for comparison. The blue section of the plot indicates the region between the BSR and the seabed. RIGHT: Hydrate saturation as a fraction of pore space, predicted with the differential effective medium frame-only model, for Vp1-Vs1 (red dots) and Vp2-Vs2 (green dots). Vp1-Vs1 gives higher values of hydrate concentration, mainly because of the higher values of Vs predicted using Castagna's relationship.

Figure 13: Variation of seismic quality factor Qp (solid line) and Qs (dashed line) with depth below seabed, derived using the frequency shift method from tomographic inversion. The curves show the variations in Qp and Qs at the centre of the tomographic model, and OBS array, close to the position of OBS 644. Variation within the model is illustrated by the Qp curves for the positions of OBS 639 (thin solid line) and OBS 648 (thin dashed line), which lie $400 \mathrm{~m}$ to north and southwest of the centre, respectively.

Figure 14: Upper: Location of site of seismic surveys on northern flank of the Storegga slide. Bathymetric contour interval is $500 \mathrm{~m}$.

Lower: Positions of OBS (black dots) and shot lines. White box encloses the area imaged with a high-resolution 3D seismic reflection survey. Bathymetric contour interval is $20 \mathrm{~m}$.

Figure 15: Single-channel seismic reflection section through the centre of the OBS array and line of OBS upslope from it at the Storegga site. The seismic source comprised two 0.65 litre sleeve guns.

Figure 16: $P$-wave velocity model for the upper part of the principal section across the Storegga site, derived from 2D travel-time inversion of reflected $P$ arrivals recorded at the OBS, 
shown as black triangles, on the seabed. White stripe shows the location of the Vp and Vs profiles shown in Figure 17. Red diagonal stripes indicate region not modelled.

Figure 17: Vertical variation of Vp and Vs derived from the 2D velocity model of Figure 16 at the position of OBS 758, at the Storegga site.

Figure 18: a) Vp without hydrate predicted by the differential effective medium model from borehole data (dashed line), and $\mathrm{Vp}$ obtained from waveform inversion of data from OBS 686 at the Storegga site. b) Hydrate concentration, as percentage of pore space, predicted from the $\mathrm{Vp}$ anomalies, using the differential effective medium models for frame-only (filled circles) and for pore-plus-frame (open circles). The estimated errors in hydrate concentration arising from uncertainty in the mineralogy and porosity of the host sediment are shown by horizontal lines through the circles. For location, see Figures 14 and 15. 


\section{FIGURES AT INTENDED SCALE FOR PUBLICATION}
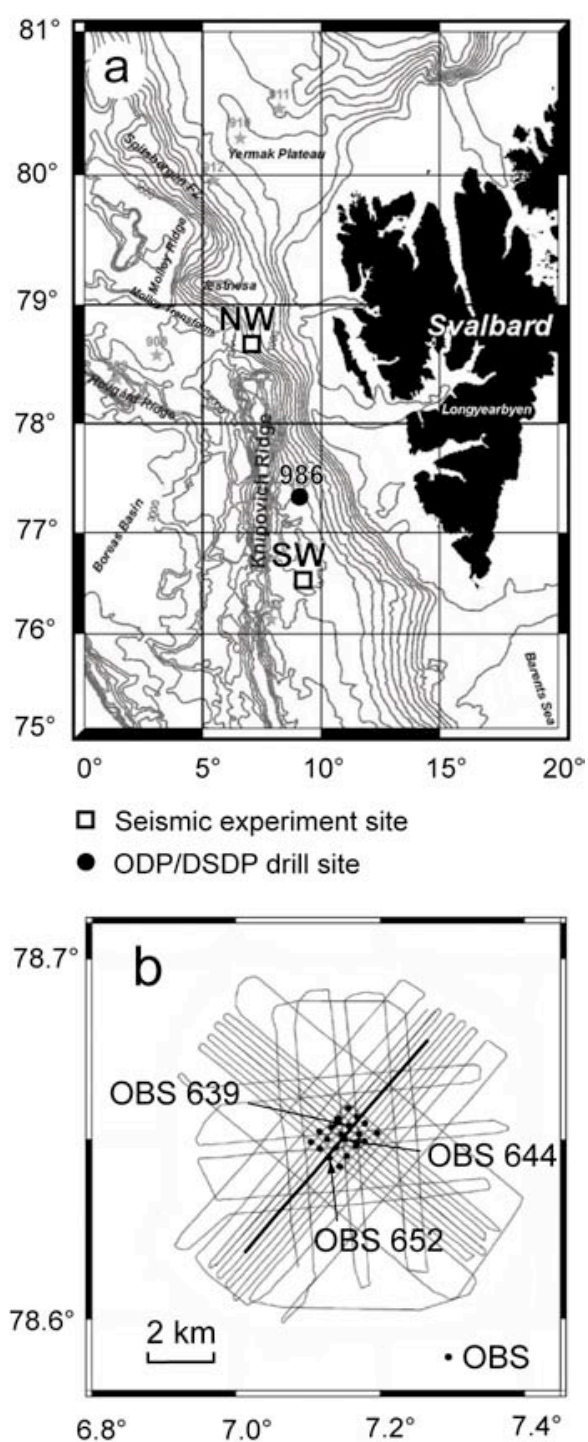

Figure 1: a) Map of the western continental margin of Svalbard, showing the two sites of HYDRATECH seismic experiments and ODP drill site 986. b) Pattern of shot lines and array of OBS at the NW site. Nominal OBS spacing is $400 \mathrm{~m}$. Line spacing is $200 \mathrm{~m}$. Shot spacing is $\leq$ 25 m. Heavy line shows the location of the seismic section illustrated in Figure 2. 


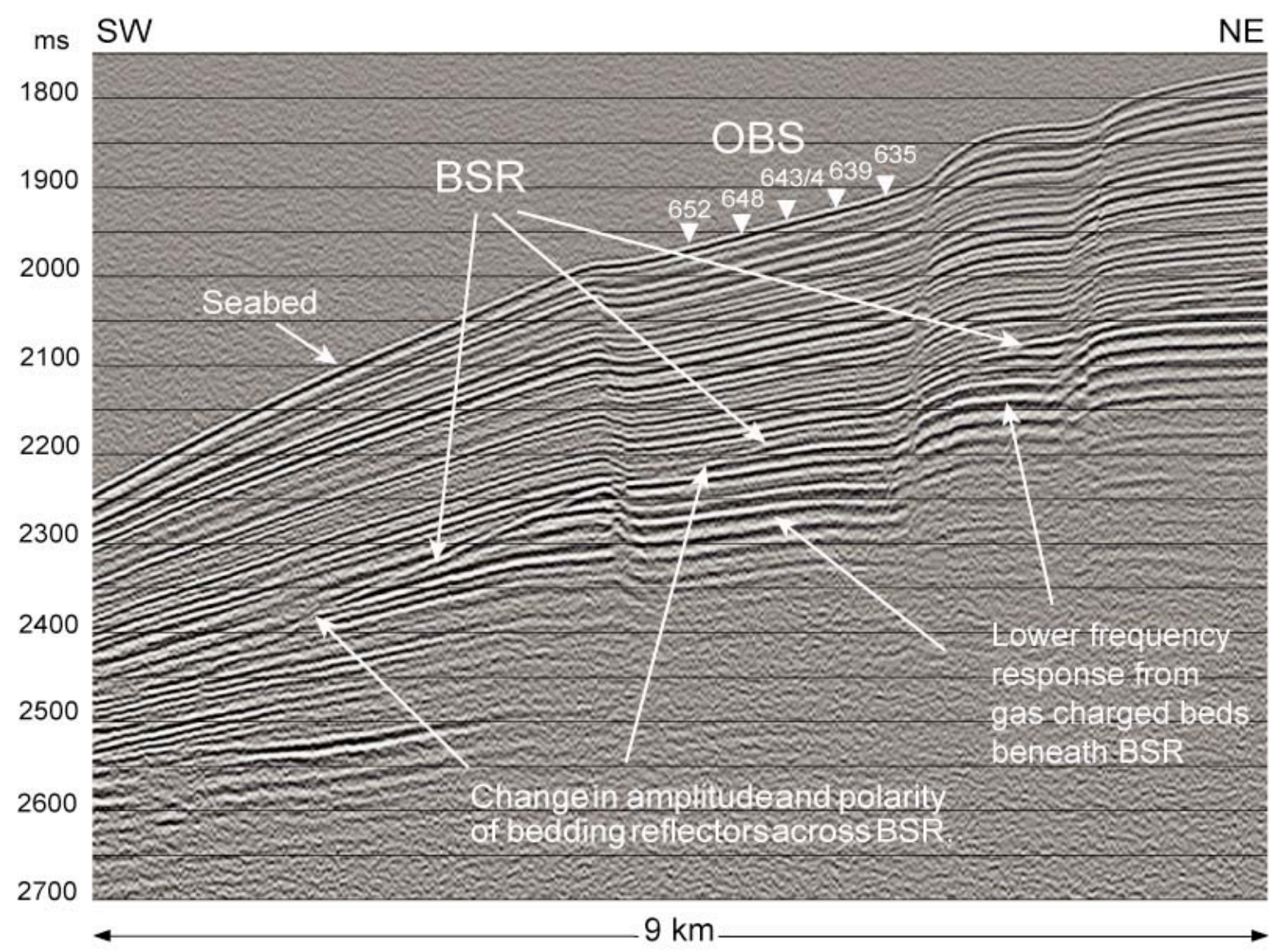

Figure 2: Seismic section from shot line 4 at the NW site (shown as heavy line in Figure 1b).

The positions of five OBS from the array shown in Fig. 1b, situated on or close to the line are shown. A BSR (bottom-simulating reflector) cuts the stratal reflectors about $300 \mathrm{~ms}$ below the seabed. 


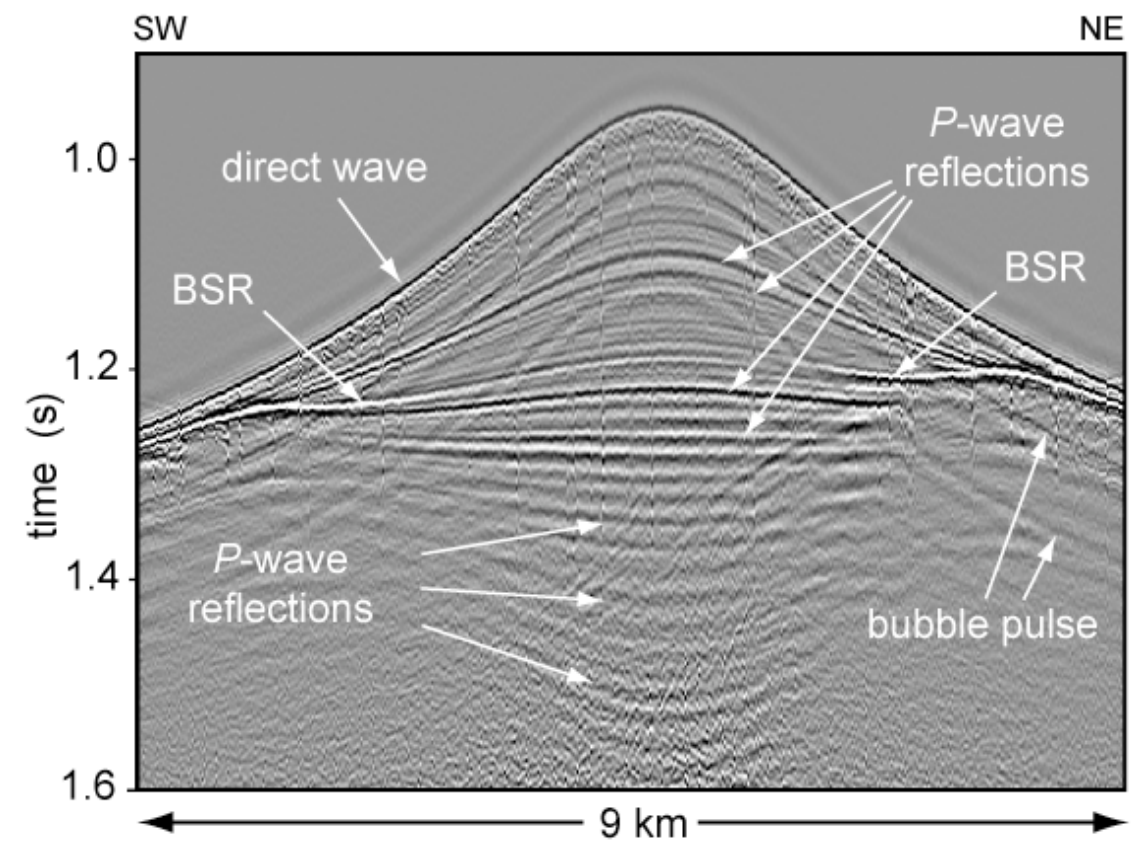

Figure 3: Grey-scale display of a gather of records from the hydrophone channel of OBS 639 at the NW Svalbard Site, showing the reflected $P$-wave arrivals. (See Fig. 2 for the position of OBS 639.) The plot has been reduced to flatten a reflector in the centre of the figure by applying a time shift to each trace that is equal to the difference between $1.25 \mathrm{~s}$ and the travel time predicted for a reflector that has $1.25 \mathrm{~s}$ travel time at zero offset. The position of the OBS is at the minimum travel time for the direct wave. Note the increase in amplitude of the BSR at far offsets and its cross-cutting relationship to the other reflectors. 


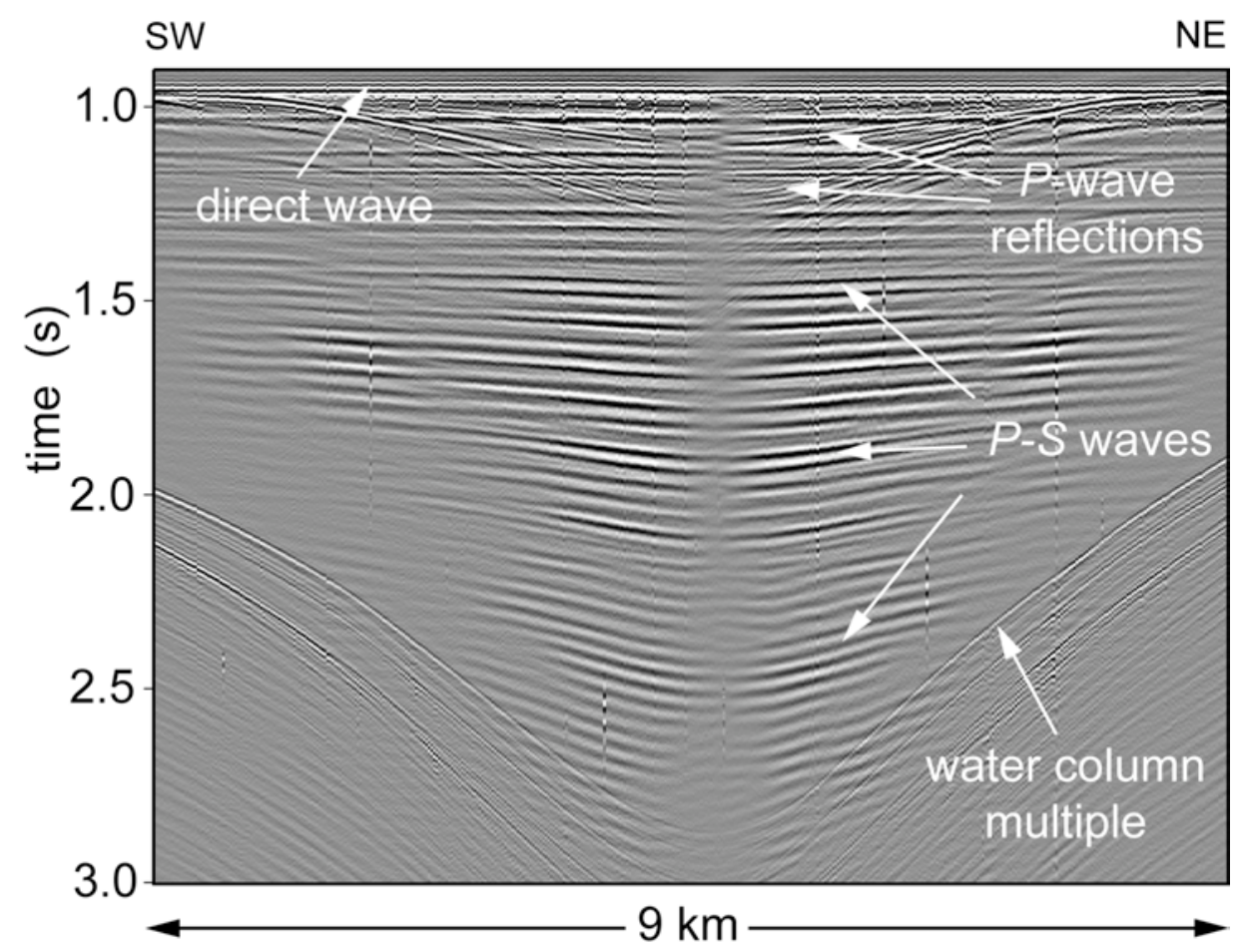

Figure 4: Grey-scale display of a gather of records of the radial component (vector combination of the two horizontal geophone records in the direction of the shot) from OBS 639 at the NW Svalbard Site, showing the $P-S$ converted waves, which have a lower dominant frequency than the $P$ waves. The plot is reduced for seawater velocity at the seabed, which flattens the direct arrival. 


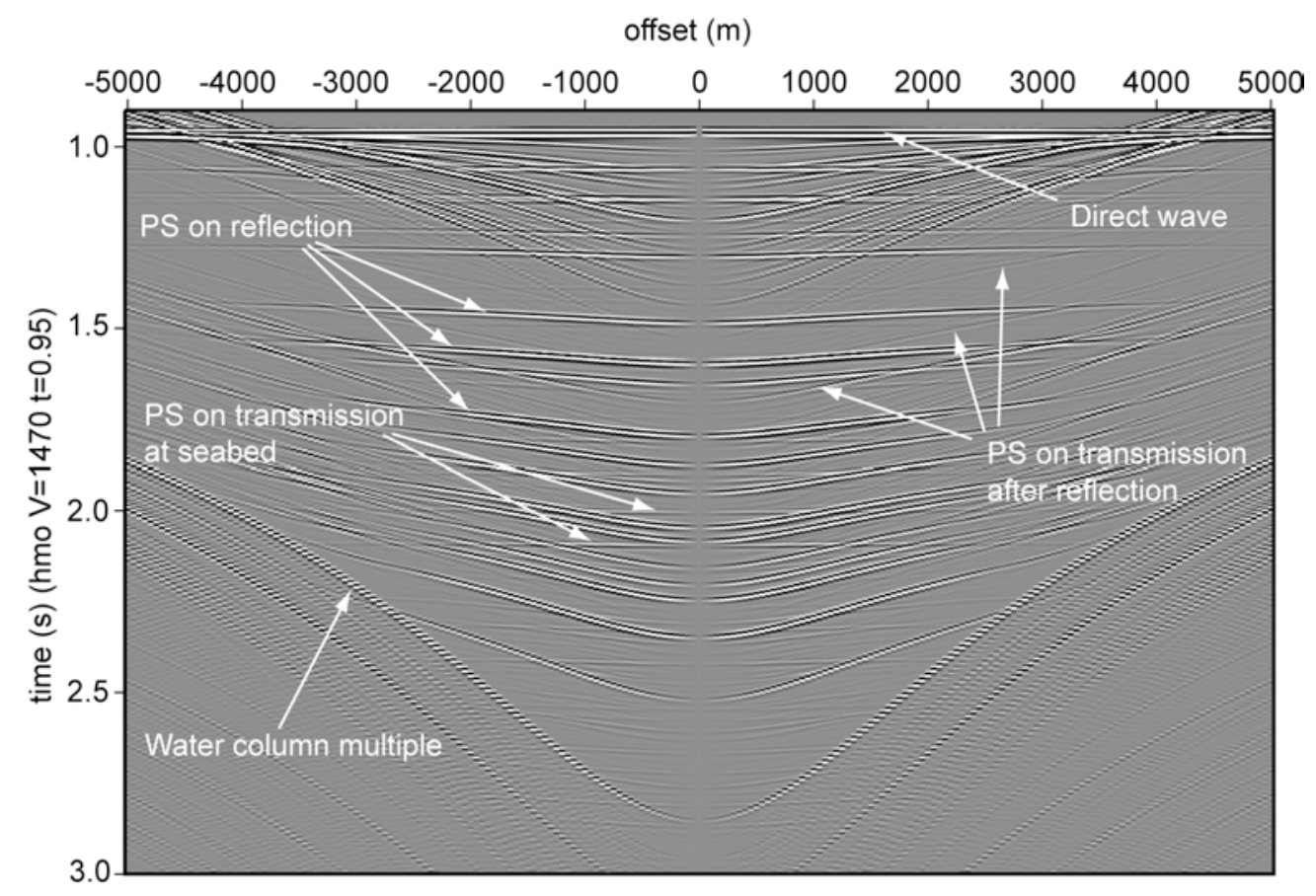

Figure 5: Synthetic seismic section generated with the reflectivity technique (Taylor, 1992) from a 1D model based on the variation of Vp and Vs with depth at the position of OBS 639 derived from 2D ray-trace inversion. The properties of the model are given in Appendix 2. As discussed in the text, Vs in the model just beneath the seabed, although lower than that derived by inversion for an 84-m-thick layer is higher than the real value, because the synthetic seismic section shows reflected $\mathrm{S}$ waves generated by PS conversion at the seabed that in the data are too weak to be seen (Figure 4). The synthetic section only shows seismic phases generated by the model, which represents only some of the reflectors, and so is sparse in comparison with the real section. 


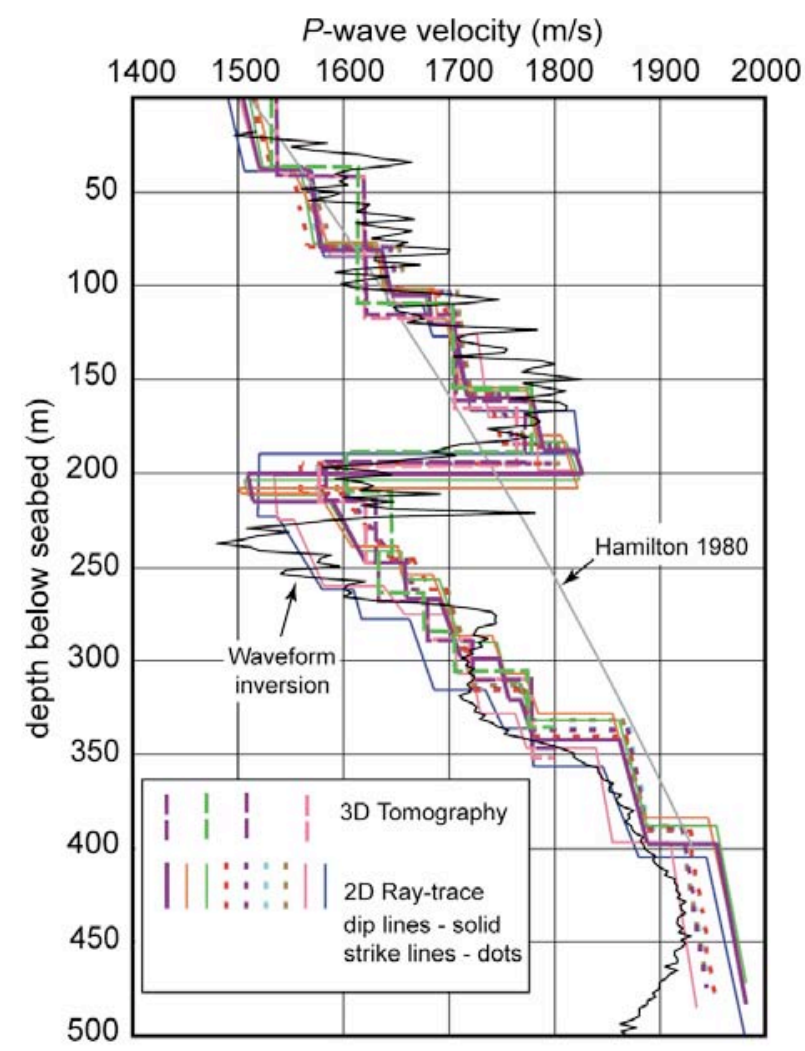

Figure 6: Comparison of the $P$-wave velocity models obtained from three different inversion techniques. $\mathrm{Vp}$ as functions of depth from the 2D ray-traced and 3D tomographic models are taken at the positions of OBS in the array. Result of 1D waveform inversion is for data from the strike-parallel shot line through OBS 639. The uppermost and lowermost parts of the tomographic model have fewer layers than the $2 \mathrm{D}$ ray-trace models. The empirical Vp-depth curve for terrigenous sediment from Hamilton (1980) is shown for comparison. 


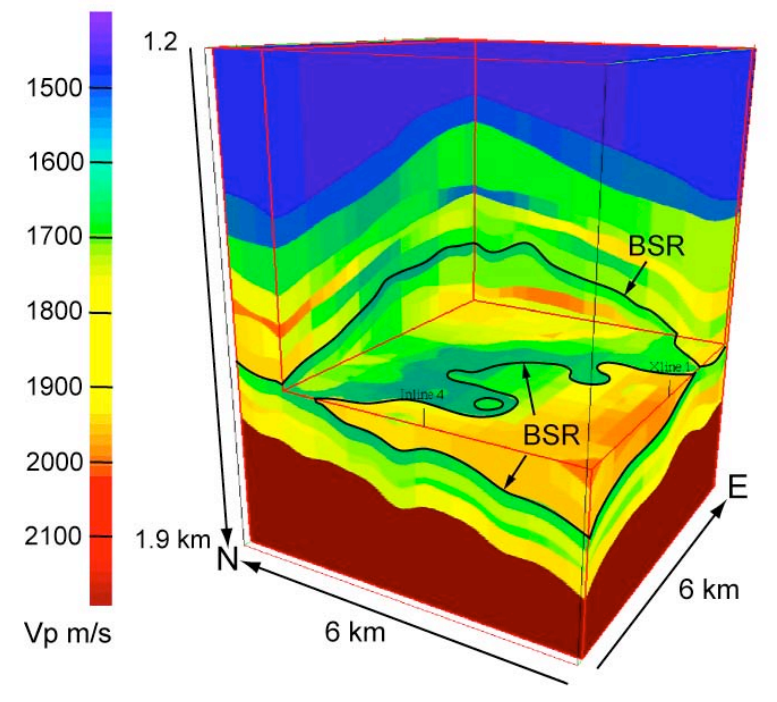

Figure 7: Sections through the tomographically derived 3D Vp model for the NW Svalbard site.

The horizontal size of the "cube" is 6 x $6 \mathrm{~km}$. Its thickness is $0.7 \mathrm{~km}$. The view is from the SW. 


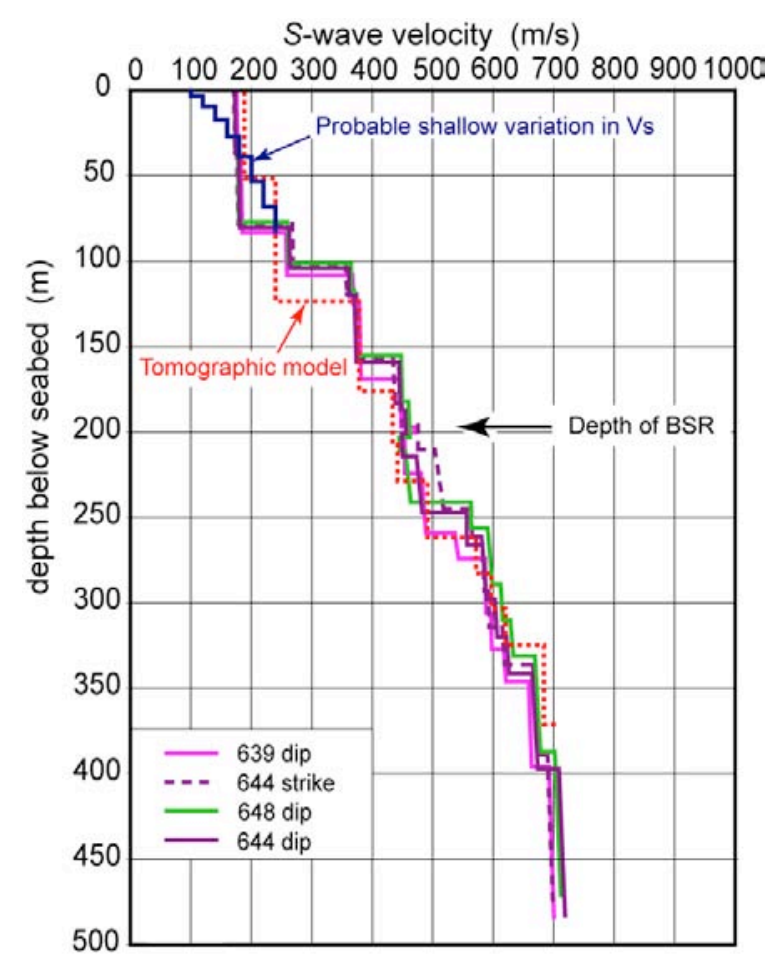

Figure 8: Comparison of $S$-wave velocity (Vs) as a function of depth at each OBS from 2D raytraced travel-time inversion with that from 3D tomographic inversion at OBS 644, NW Svalbard. The tomographic model has fewer layers in the upper and lower parts of the model. Both models lack sufficient layers with clear $P-S$ arrivals in the uppermost $80 \mathrm{~m}$ to be able to define the variation in Vs with depth properly. The blue curve shows a likely variation of Vs, based on results from similar sediment sequences elsewhere (e.g. Nolet and Dorman (1966)), that satisfies the travel times for the shallowest $P-S$ converting interface. 

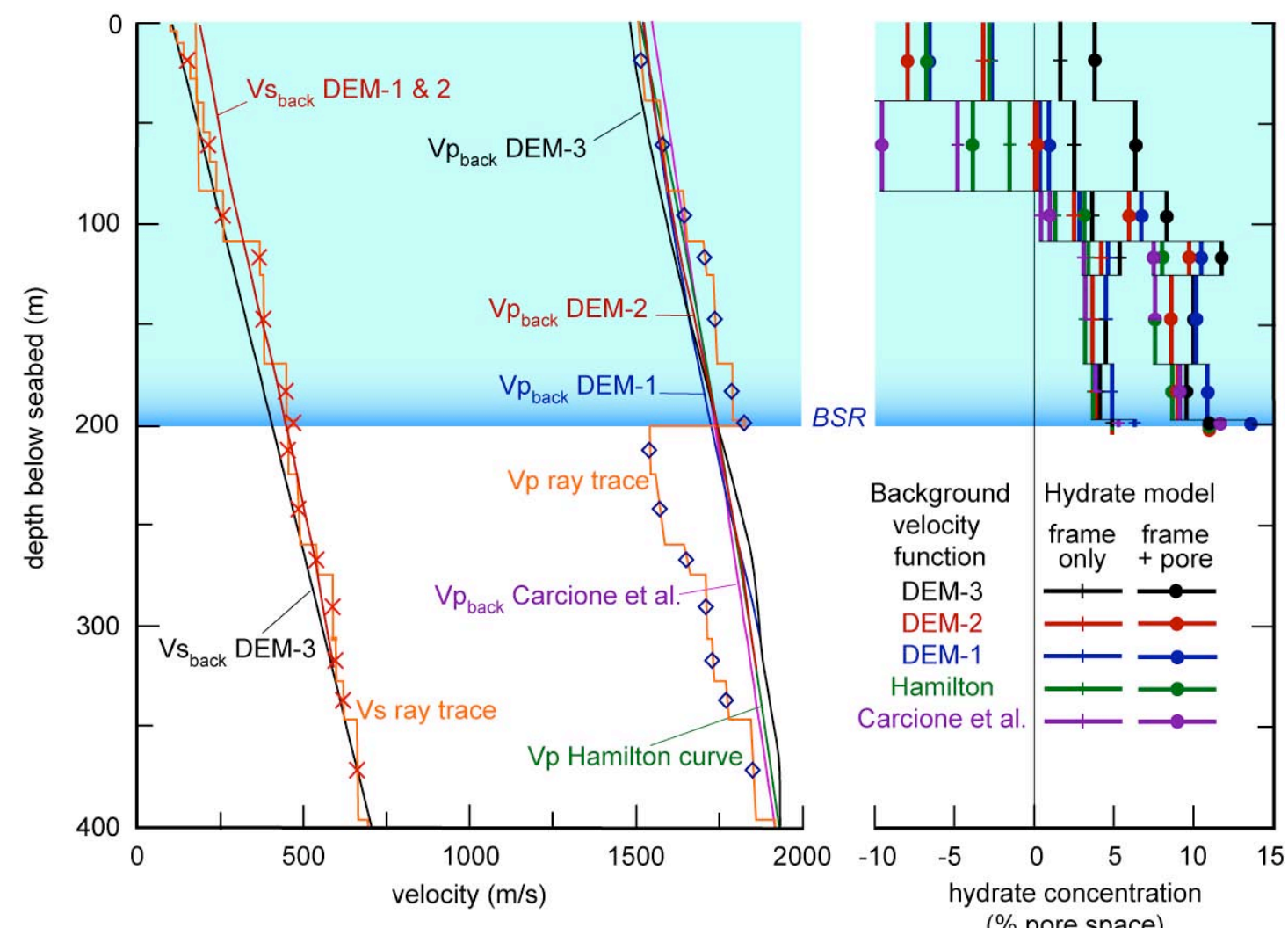

Figure 9: Comparison of estimated hydrate concentration derived from the same ray-tracingderived variation of $\mathrm{Vp}$ and $\mathrm{Vs}$ with depth at the position of OBS 639, using different background velocity curves for the expected variation of velocity with depth in the absence of hydrate. The values of hydrate concentration were calculated from the average Vs and Vp for each layer (shown by the crosses and diamonds on the Vs and Vp curves respectively). The blue section of the plot indicates the region between the BSR and the seabed. A differential effective medium model in which the hydrate forms a connected framework (frame-only model) gives lower values of hydrate concentration. A differential effective medium model in which hydrate partially fills pore space as well as forming a framework (frame-plus-pore model) gives higher predicted of halues concentration. 


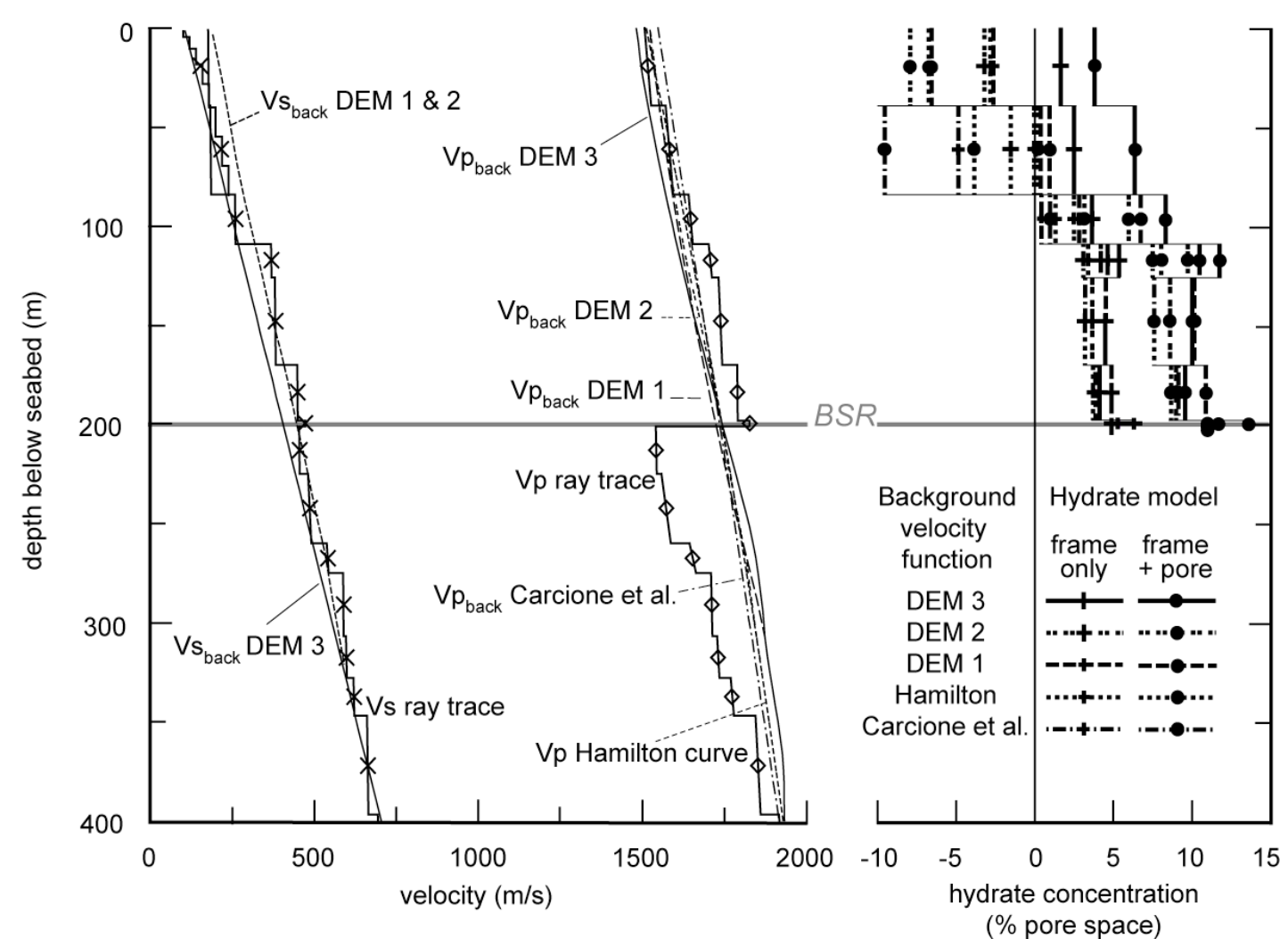

Figure 9: Comparison of estimated hydrate concentration derived from the same ray-tracingderived variation of $\mathrm{Vp}$ and $\mathrm{Vs}$ with depth at the position of OBS 639, using different background velocity curves for the expected variation of velocity with depth in the absence of hydrate. The values of hydrate concentration were calculated from the average Vs and Vp for each layer (shown by the crosses and diamonds on the Vs and Vp curves respectively). The grey line shows the position of the BSR. A differential effective medium model in which the hydrate forms a connected framework (frame-only model) gives lower values of hydrate concentration. A differential effective medium model in which hydrate partially fills pore space as well as forming a framework (frame-plus-pore model) gives higher predicted values of hydrate concentration. 
Hydrate Saturation (\% pore space)

10987655432210

Line 4

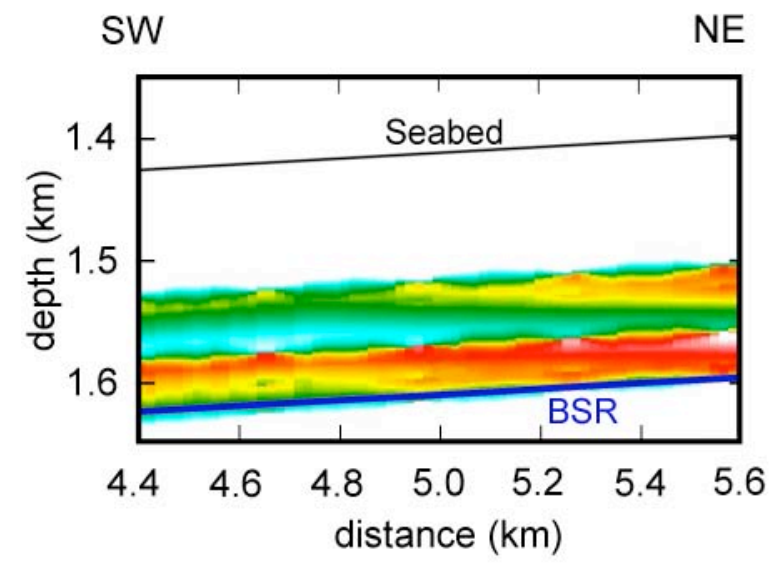

Figure 10: Concentration of hydrate in pore space, derived from the variation in $\mathrm{Vp}$ and $\mathrm{Vs}$ in a 2D model along shot line 4 obtained by travel-time inversion. The differential effective medium frame-only model of Chand et al. (2006) was used to estimate hydrate concentration. The dark blue line shows the position of the BSR.. 


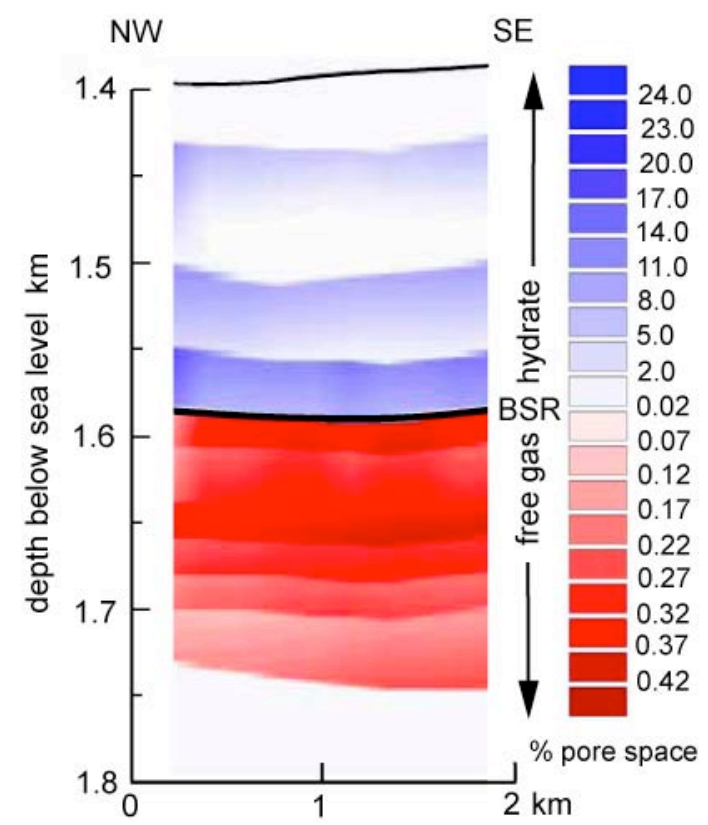

Figure 11: Concentration of hydrate above the BSR and free gas below the BSR, predicted with the model of Carcione et al. (2005), derived from a NW-SE section of the tomographic Vp model through the centre of the OBS array at the NW Svalbard site. 

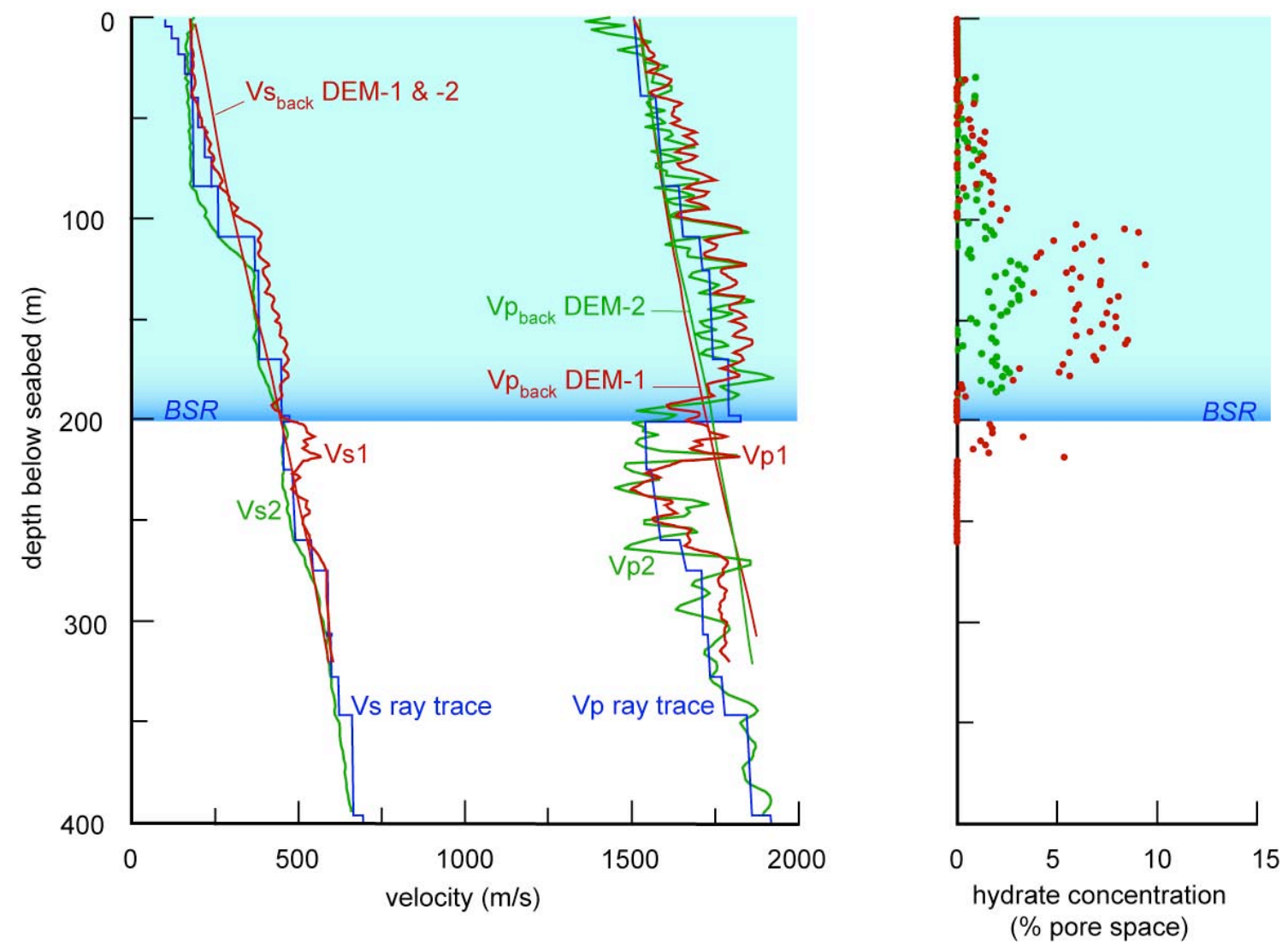

Figure 12: LEFT: Vs and Vp derived from waveform inversion at OBS 639. Vs1 is derived from Vp1 via Castagna's relationship (red curve) and Vs2 and Vp2 are both obtained from the inversion (green curve). Also shown are the background values of Vp and Vs in the absence of hydrate predicted by the differential effective medium model (DEM-1, used with the red curve, and DEM-2 used with the green curve). The values of Vp and Vs obtained from the ray-traced model are shown for comparison. The blue section of the plot indicates the region between the BSR and the seabed. RIGHT: Hydrate saturation as a fraction of pore space, predicted with the differential effective medium frame-only model, for Vp1-Vs1 (red dots) and Vp2-Vs2 (green dots). Vp1-Vs1 gives higher values of hydrate concentration, mainly because of the higher values of Vs predicted using Castagna's relationship. 
Monochrome version
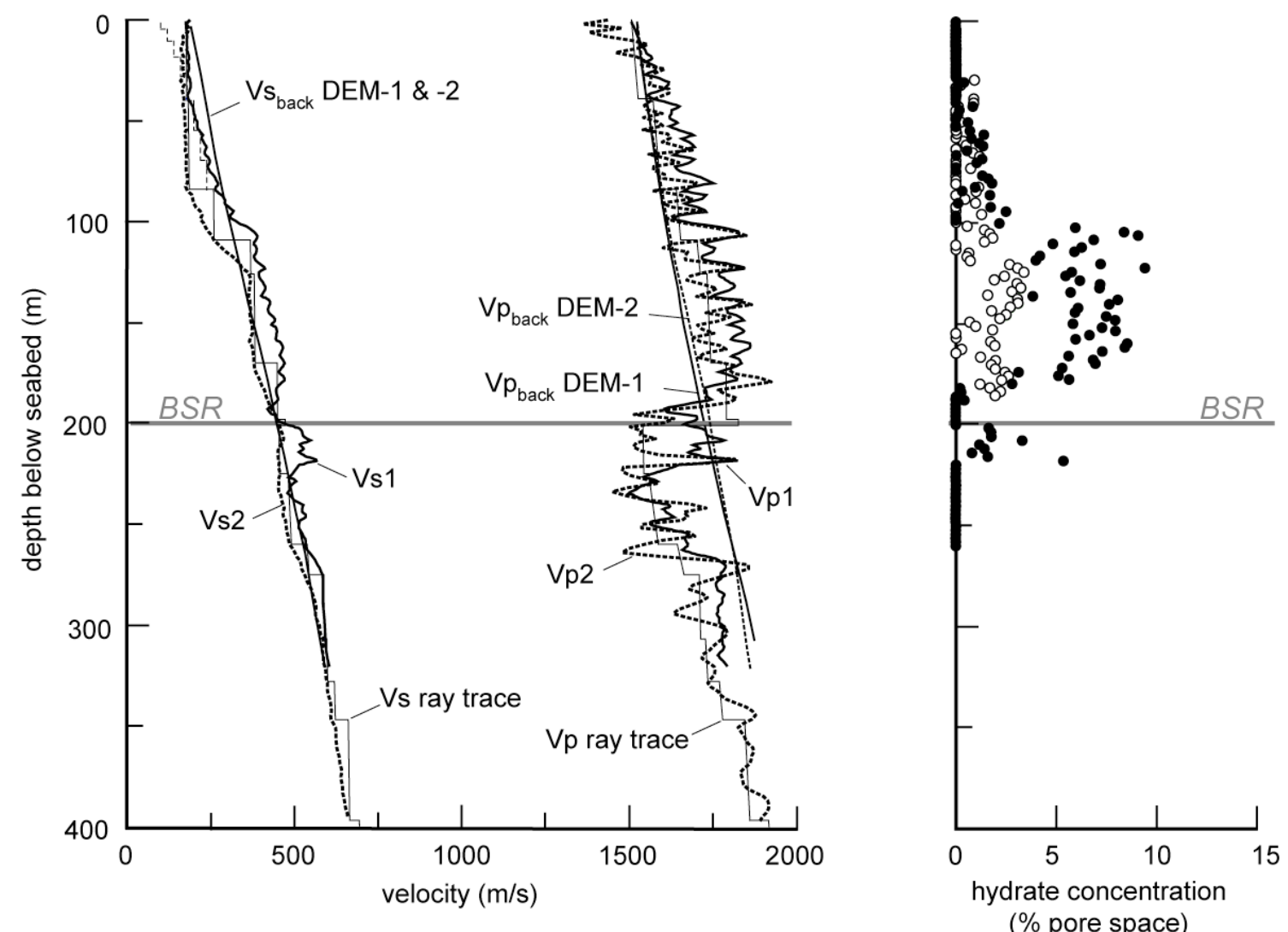

Figure 12: LEFT: Vs and Vp derived from waveform inversion at OBS 639. Vs1 is derived from Vp1 via Castagna's relationship (red curve) and Vs2 and Vp2 are both obtained from the inversion (green curve). Also shown are the background values of Vp and Vs in the absence of hydrate predicted by the differential effective medium model (DEM-1, used with the red curve, and DEM-2 used with the green curve). The values of Vp and Vs obtained from the ray-traced model are shown for comparison. The grey line shows the position of the BSR. RIGHT: Hydrate saturation as a fraction of pore space, predicted with the differential effective medium frame-only model, for Vp1-Vs1 (filled circles) and Vp2-Vs2 (open circles). Vp1-Vs1 gives higher values of hydrate concentration, mainly because of the higher values of Vs predicted using Castagna's relationship. 


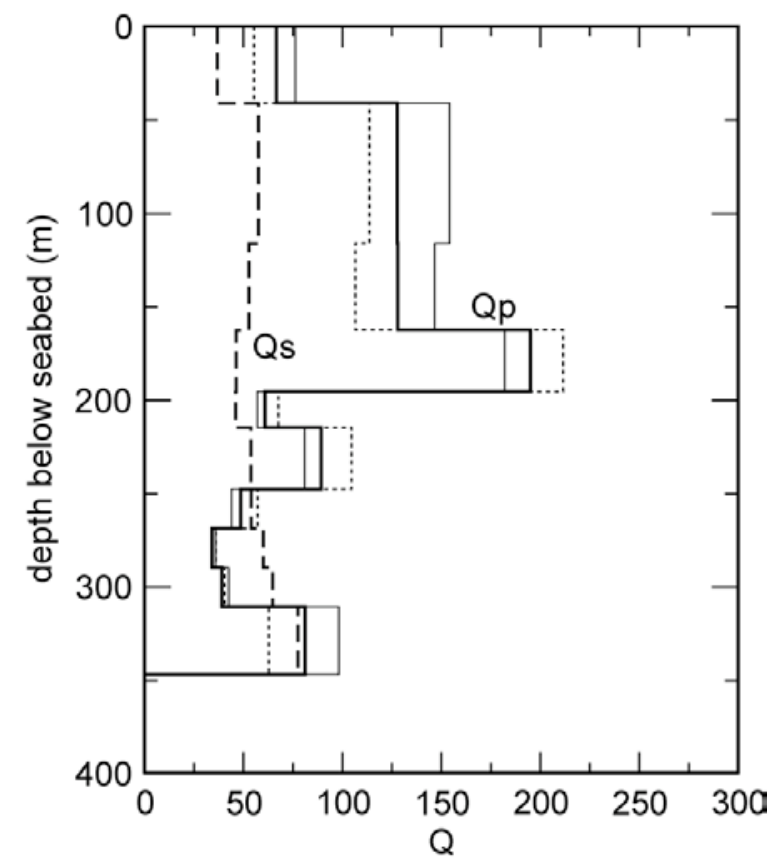

Figure 13: Variation of seismic quality factor Qp (solid line) and Qs (dashed line) with depth below seabed, derived using the frequency shift method from tomographic inversion. The curves show the variations in Qp and Qs at the centre of the tomographic model, and OBS array, close to the position of OBS 644. Variation within the model is illustrated by the Qp curves for the positions of OBS 639 (thin solid line) and OBS 648 (thin dashed line), which lie $400 \mathrm{~m}$ to north and southwest of the centre, respectively. 


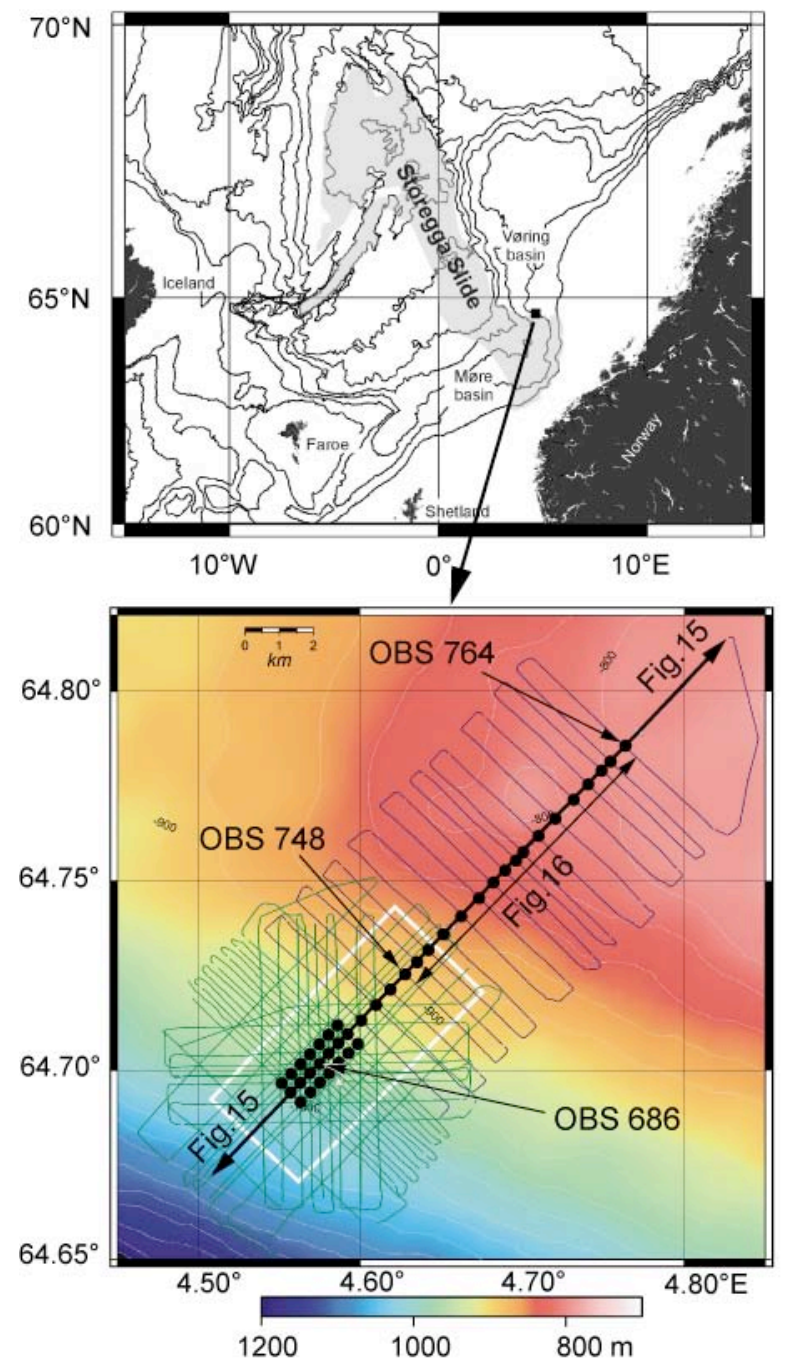

Figure 14: Upper: Location of site of seismic surveys on northern flank of the Storegga slide. Bathymetric contour interval is $500 \mathrm{~m}$.

Lower: Positions of OBS (black dots) and shot lines. White box encloses the area imaged with a high-resolution 3D seismic reflection survey. Bathymetric contour interval is $20 \mathrm{~m}$ (white lines). 


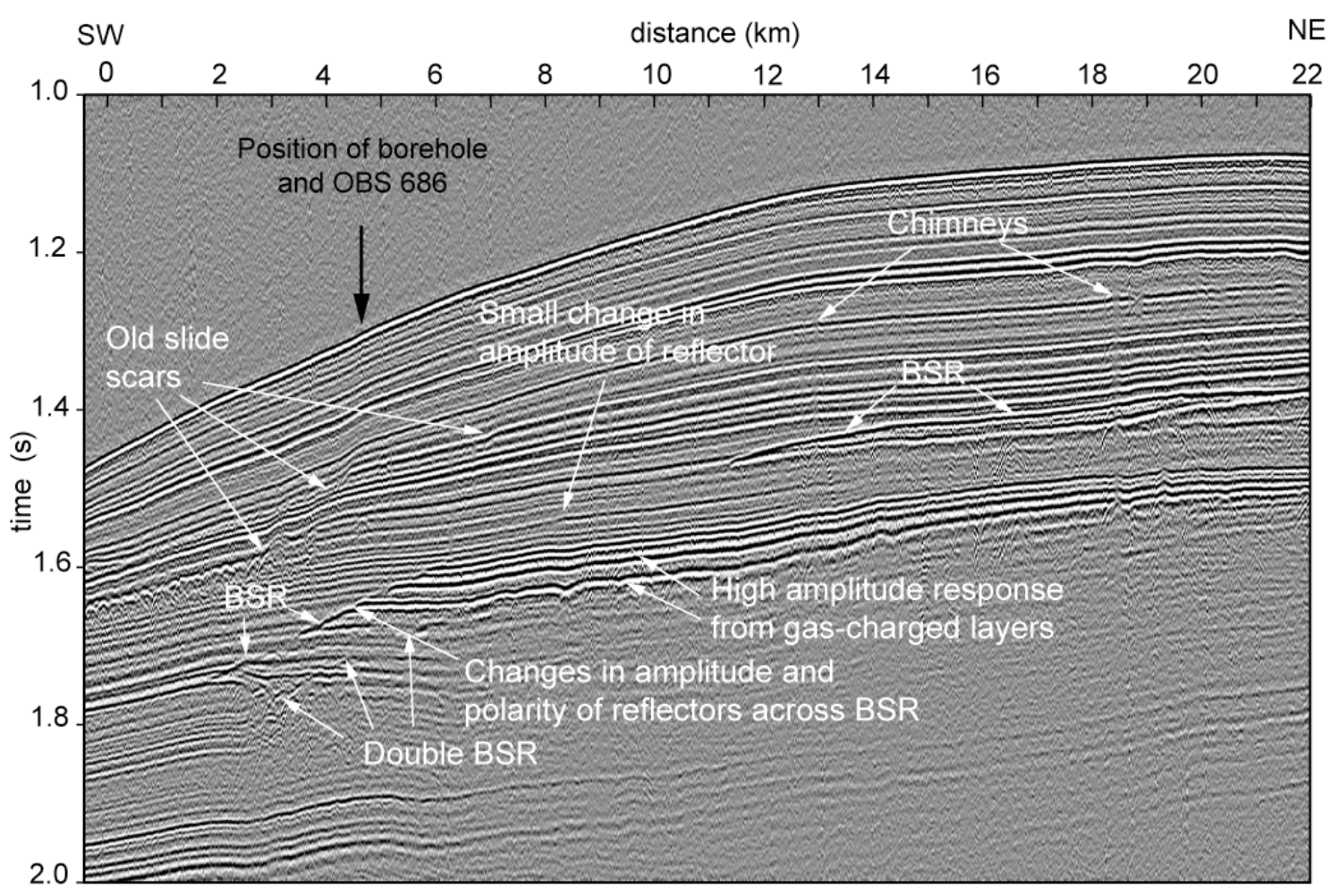

Figure 15: Single-channel seismic reflection section through the centre of the OBS array and line of OBS upslope from it at the Storegga site. The seismic source comprised two 0.65 litre sleeve guns. 


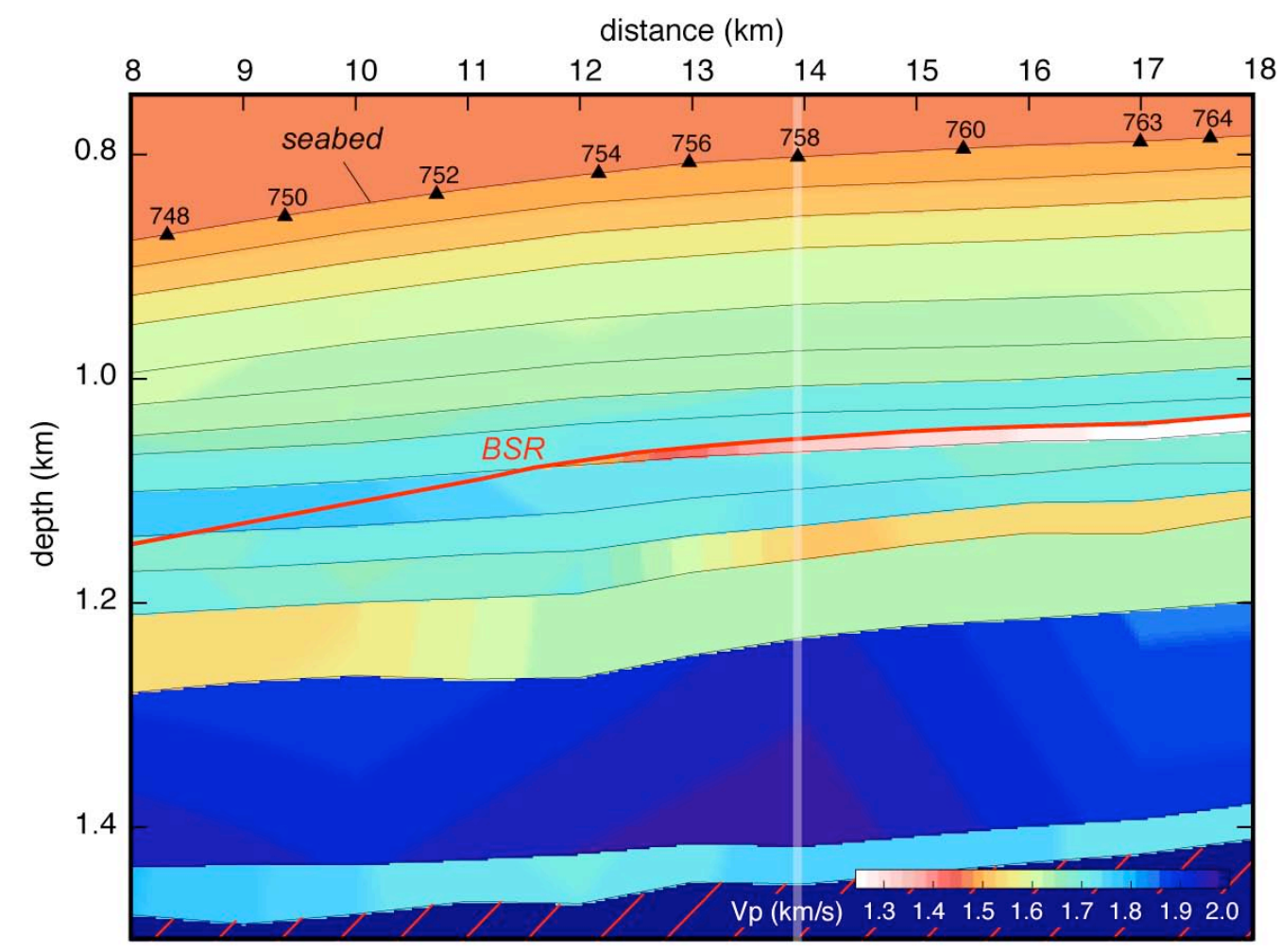

Figure 16: $P$-wave velocity model for the upper part of the principal section across the Storegga site, derived from 2D travel-time inversion of reflected $P$ arrivals recorded at the OBS, shown as black triangles, on the seabed. White stripe shows the location of the Vp and Vs profiles shown in Figure 17. Red diagonal stripes indicate region not modelled. 


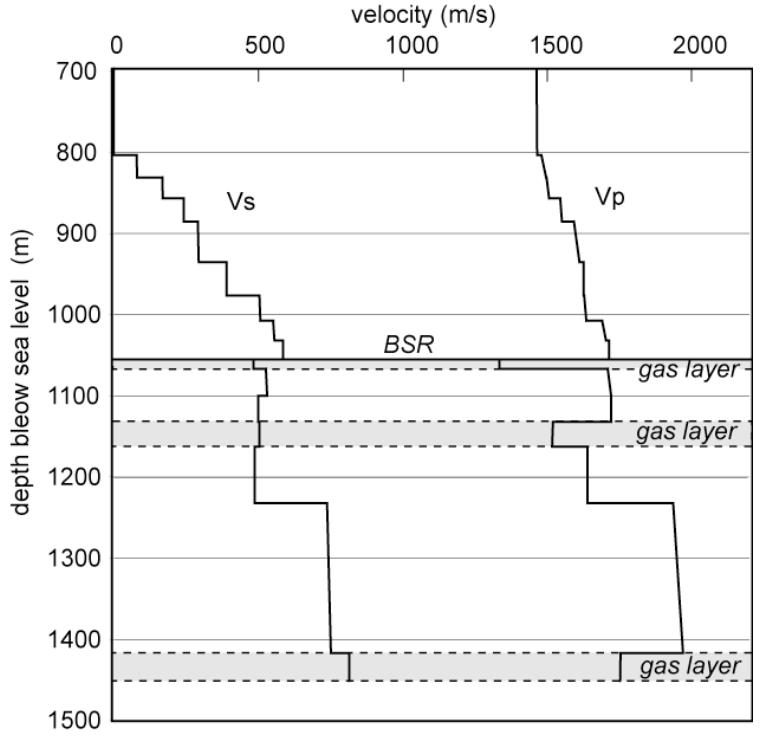

Figure 17: Vertical variation of $\mathrm{Vp}$ and $\mathrm{Vs}$ derived from the 2D velocity model of Figure 16 at the position of OBS 758, at the Storegga site. 

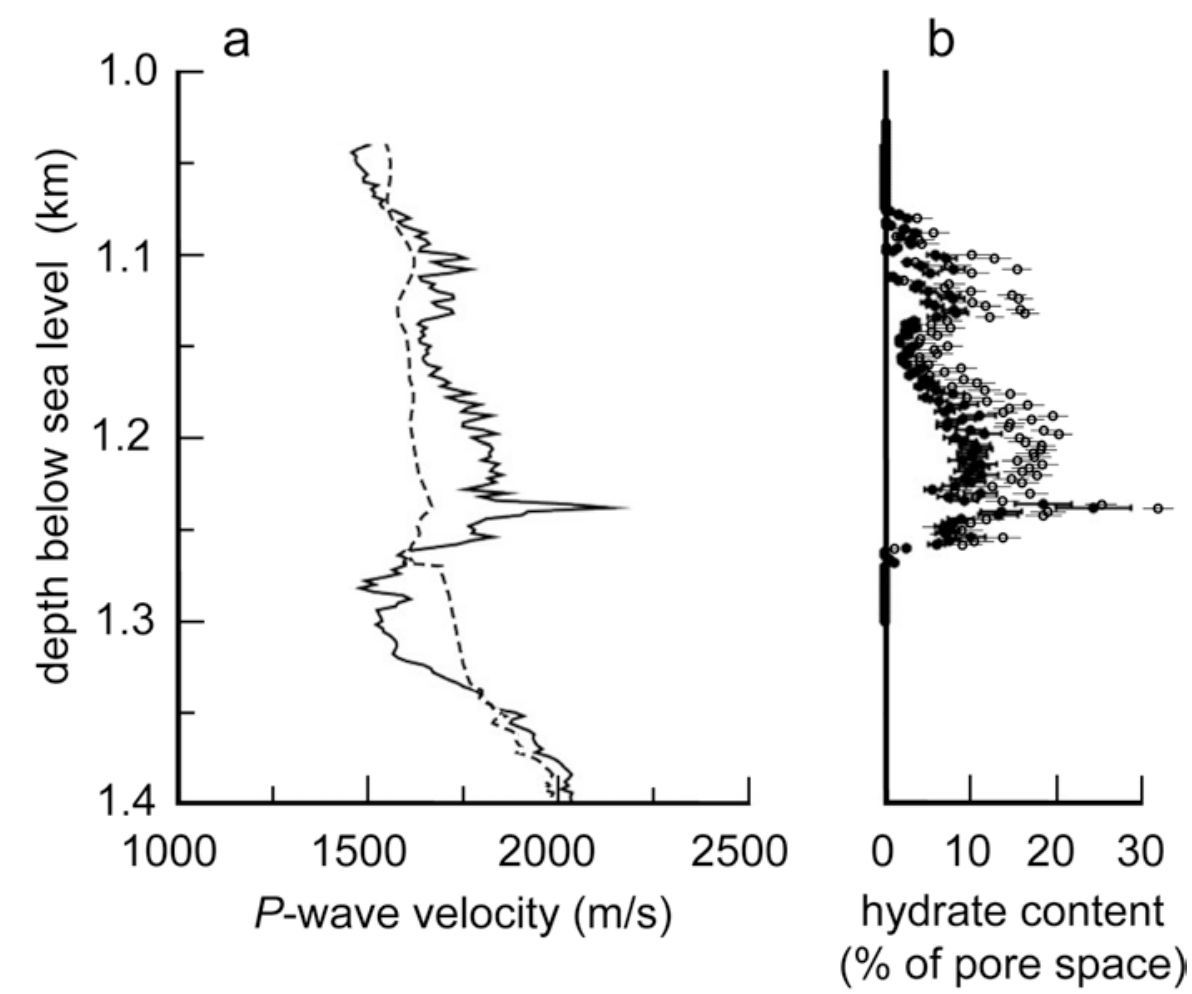

Figure 18: a) Vp without hydrate predicted by the differential effective medium model from borehole data (dashed line), and Vp obtained from waveform inversion of data from OBS 686 at the Storegga site. b) Hydrate concentration, as percentage of pore space, predicted from the Vp anomalies, using the differential effective medium models for frame-only (filled circles) and for pore-plus-frame (open circles). The estimated errors in hydrate concentration arising from uncertainty in the mineralogy and porosity of the host sediment are shown by horizontal lines through the circles. For location, see Figures 14 and 15. 